\title{
Technological innovations, downside risk, and the modernization of agriculture
}

\author{
Kyle Emerick, ${ }^{1}$ Alain de Janvry ${ }^{2}$, Elisabeth Sadoulet ${ }^{2}$ and Manzoor H. Dar ${ }^{3}$
}

October 6, 2015

\begin{abstract}
We use a randomized experiment in India to show that improved technology enhances agricultural productivity by crowding in modern inputs and cultivation practices. Specifically, we show that a new rice variety that reduces downside risk by providing flood tolerance has positive effects on adoption of a more labor intensive planting method, area cultivated, fertilizer usage, and credit demand. We find that a large share of the expected gains from new technology comes from crowding in of other investments. Therefore, improved technologies that reduce risk by protecting production in bad years have the potential to increase agricultural productivity in normal years.
\end{abstract}

JEL codes: O30, O13

\footnotetext{
${ }^{1}$ Department of Economics, Tufts University. ${ }^{2}$ Department of Agricultural and Resource Economics, University of California at Berkeley. ${ }^{3}$ International Rice Research Institute, New Delhi India. We acknowledge financial support from the Agricultural Technology Adoption Initiative of the Bill and Melinda Gates Foundation and from the Stress-Tolerant Rice for Africa and South Asia (STRASA) project of the CGIAR. We thank Marshall Burke, Michael Carter, Kelsey Jack, Ted Miguel, Tavneet Suri, and Mushfiq Mobarak for helpful comments and suggestions. We also thank seminar audiences at UC Berkeley, University of Connecticut, Tufts University, and the 2014 BREAD workshop for useful suggestions. We are grateful to the staff at the Balasore Social Service Society for outstanding work in the field.
} 


\section{Introduction}

Productivity growth in the agricultural sector is recognized as an important driver of structural transformation and economic growth for poor countries (Gollin, Parente, and Rogerson, 2002). At the same time, agricultural productivity has been hindered by the failure of farmers in developing countries to use high levels of modern inputs and to adopt improved agricultural practices. Fertilizer is an oft-cited example. African farmers use fertilizers at much lower rates than farmers in the rest of the world (World Bank, 2008). Similarly, farmers in the lowest-productivity rice-producing states in Eastern India use less than half the fertilizer of those in the higher-productivity states in the country. ${ }^{1}$

Several explanations for limited modern input use and the failure to adopt improved practices have arisen in the literature. These include procrastination and time inconsistent preferences (Duflo, Kremer, and Robinson, 2011), high transaction costs due to poor infrastructure (Suri, 2011), lack of information and difficulties in learning (Ashraf, Giné, and Karlan, 2009; Hanna, Mullainathan, and Schwartzstein, 2014), and absence of formal insurance (Karlan et al., 2014). An additional plausible explanation - this time on the supply side of technology — is that smallholder farmers lack the technologies that are well-suited to local conditions and therefore factor deepening and adoption of other improved agricultural practices are not optimal. Put differently, can the availability of new technologies that are better-suited to local conditions crowd in additional inputs and investments in other productivity-enhancing practices?

In this paper we answer this question by showing that technological innovation in agriculture can itself create a factor deepening effect where improved practices and additional inputs are used in response to innovation. Specifically, we study the dissemination of an innovative new rice variety that is well-suited to local conditions in flood-prone areas because its key feature is flood tolerance. The technology reduces downside risk by decreasing crop damage during flooding, while at the same time leaving production unaffected during normal years.

Our experiment was carried out over two years in the eastern Indian state of Odisha. We randomized the distribution of a new rice variety called Swarna-Sub1 across 128 villages. This seed variety is nearly identical to Swarna, the popular high-yielding variety grown in this area, with the only difference being improved flood tolerance. ${ }^{2}$ Prior to the 2011 wet

\footnotetext{
${ }^{1}$ We used the ICRISAT district-level database for all of India to calculate fertilizer use per hectare and rice yield during 2007. The lowest productivity states producing a large amount of rice are Odisha, Jharkhand, Chattisgarh, and Assam. Fertilizer use per hectare varies from 73 to $110 \mathrm{~kg}$ per hectare in these states. In contrast, fertilizer use is over double and productivity is substantially higher in other rice producing states such as West Bengal and Andhra Pradesh.

${ }^{2}$ Elongation is the natural response of the rice plant to flooding. However, the plant loses its stored energy
} 
season, a random subset of five farmers in each of 64 treatment villages were provided a small package of Swarna-Sub1 seed. This "minikit" contained only seeds and a short information sheet on the properties of Swarna-Sub1. The comparison farmers in the remaining villages were not provided with any seeds, as Swarna is widely grown in the area.

In general, our main finding is that this technological innovation leads to not only avoided yield losses under flooding but also significant factor deepening and adoption of improved practices as indirect benefits in normal years. ${ }^{3}$ More specifically, we have four sets of findings. First, the new technology modernizes farmers' production practices. During both years, treatment farmers are less likely to use the traditional planting method of manually broadcasting seedlings. Instead, they are more likely to use the more labor intensive manual transplantation method. Specifically, plots cultivated by treatment farmers are $22 \%$ less likely to be planted using broadcasting in year one. This effect rises to approximately $33 \%$ during the second year of the experiment. In addition, plots cultivated by treatment farmers are around $14 \%$ less likely to be cultivated with traditional seed varieties that are generally more flood tolerant but lower yielding on average than the Swarna variety. Finally, we show some evidence that availability of these new seeds causes more area to be cultivated, partly due to decreased fallowing of low-lying and low quality lands during year two.

Second, we show that improved technology crowds in more fertilizer use. Conditional on total area cultivated, farmers given access to better technology spend around 10\% more on fertilizer during the second year of cultivation. This effect is entirely concentrated on the types of fertilizer that are used earlier in the growing season closer to planting time when the risk of crop loss due to flooding is high.

Our third set of findings is on credit usage and savings behavior. Treatment farmers are $36 \%$ more likely to utilize credit during year two. These loans are primarily agricultural loans distributed by local cooperatives early in the growing season. This effect can plausibly be explained by either demand or supply side responses in the credit market. That is, the technology decreases the probability of the low production state, which could increase the demand for credit. Alternatively, reducing downside risk could increase the supply of credit by decreasing default risk. Our design does not allow us to distinguish between these

while elongating and fails to regrow after floodwaters recede. Swarna-Sub1 represses this elongation response and allows the plant to more effectively grow after flooding ends (Xu et al., 2006; Fukao and Bailey-Serres, 2008). Excluding flood tolerance, Swarna-Sub1 is otherwise genetically identical to Swarna - a fact that has been extensively documented by agricultural scientists (Neeraja et al., 2007; Bailey-Serres et al., 2010; Mackill et al., 2012). Therefore, the technology reduces downside risk by reducing the loss in yield during flooding while leaving it unaffected during normal years. This has been shown in agronomic trials (Singh, Mackill, and Ismail, 2009). We verify the agronomic property of the technology in farmers' fields using variation in the length of flooding during year one of our study (Dar et al., 2013).

${ }^{3}$ We focus our analysis on rice in the wet season because it is the main crop for a vast majority of the sample. Due to a lack of irrigation only $20 \%$ of farmers in the sample grow a dry season crop. 
alternative mechanisms. ${ }^{4}$

Farmers given access to improved technology also reduce the share of the harvest that is stored for future consumption by five percentage points. A plausible interpretation of this finding is that reducing downside risk with innovation decreases the need to store rice in order to protect against future production variability. Two facts are consistent with this explanation. First, a simple calculation shows that after harvest households set aside more rice than is needed to feed their family for the entire year. Second, the effect of the technology on the storage rate is smaller for households that are at least partially insured by access to government subsidized rice. However, we cannot fully rule out alternative explanations and thus we interpret these results with caution.

Fourth, we quantify the effects of crowd-in on productivity by exploiting the fact that the second year of our experiment was a non-flood year. Given that the new and old technologies are identical when there is no flooding, there should be no productivity effects in the absence of any increased investment by farmers. Instead, we show that access to the technology caused rice yield to increase by approximately 280 kilograms per hectare, or around $10 \%$. We consider this to be the overall crowd-in effect of the new technology on agricultural productivity. $^{5}$

How large are these indirect benefits of the new technology when compared to the expected agronomic benefits of the technology over time? We use two pieces of information to calculate expected agronomic benefits: the measured yield benefits obtained on experimental plots conditional on flooding and the average probability of flooding for fields in our sample. Starting with the probability of flooding, we use GIS coordinates of plots in our sample along with 11 years of satellite imagery to approximate the probability that a plot in the sample will be flooded in a given year. We find this probability to be approximately 0.19 . We combine this with evidence from controlled laboratory experiments showing the maximum yield gain of Swarna-Sub1 under flooding to be approximately 2 tons per hectare (Singh, Mackill, and Ismail, 2009). ${ }^{6}$ Combining the two estimates, the expected yield gain due to the purely

\footnotetext{
${ }^{4}$ The supply side explanation seems more likely given that loan liabilities are often waived by cooperatives after years of heavy flooding or drought.

${ }^{5}$ Separating the effect of a new technology into purely technical (agronomic) and crowd-in effects is indeed challenging from an empirical standpoint (Beaman et al., 2013). Focusing on new seed varieties in agriculture, the only attempt at separating the agronomic benefits from gains due to crowd-in rely on time series decompositions where complementary inputs are measured as a TFP residual in productivity regressions (Evenson and Gollin, 2003).

${ }^{6}$ This estimate is in the range of estimates from other controlled on-farm trials discussed in Mackill et al. (2012). However, this is a very conservative upper-bound estimate for the absolute gains in farmers' fields because baseline yields of farmers in our sample under normal conditions are approximately only $60 \%$ of those observed in controlled on-farm trials. In addition, controlled trials show that the two technologies produce similar yields when submergence does not occur (Singh, Mackill, and Ismail, 2009).
} 
technical features of the technology is at most 380 kilograms per hectare. This is striking given that crowd-in induces yield gains of around 280 kilograms per hectare. Put differently, crowd-in accounts for at least $43 \%$ of the overall yield gains of the new technology.

What is the mechanism that explains why these new technologies generate gains through inducing adoption of other inputs and practices? We posit a simple household model that highlights two important channels. First, by reducing losses during flooding, the technology could have a direct effect on the marginal product of inputs. This would naturally generate factor deepening. Second, there is a downside risk effect which results from the fact that the technology increases overall output and income in low-productivity states when the marginal product of input use is low. Reducing downside risk in this way has the effect of both increasing the expected income (the first moment) and reducing the variance of income (the true risk factor).

While our experiment is not designed to distinguish between these explanations, we give suggestive evidence that the risk effect is an important channel. We show that effects on decision-making exist — but are smaller — on plots that are not cultivated with the new technology. This result suggests that shifting input demands due to effects on marginal productivity cannot be the only explanation of the results. However, this is only suggestive evidence because there is undoubtedly selection on the types of plots where the new technology is cultivated. We attempt to reduce such selection concerns by including controls for plot characteristics as well as by selectively dropping the lowest-productivity plots of control farmers during this analysis.

We also provide some supporting evidence that the expected income channel cannot explain the observed factor deepening. We exploit variation in flood intensity during the first year of the study to calculate the duration of the flood shock that would generate a change in income that is roughly equivalent to the expected productivity gain of the new technology. This equivalent flood shock should generate effects that are of a similar magnitude to our estimated effects if our results are explained by the expected income channel. We do not find evidence for this in the data.

Technologies such as this that make staple crops more tolerant to droughts and floods are a major recent innovation in agriculture. While the Green Revolution benefited much of the world, it is well-recognized that rainfed areas that are prone to weather extremes benefited much less. The development of technologies that are more tolerant to weather extremes is considered to be one of the key components of the world's next Green Revolution (Pingali, 2012). ${ }^{7}$ Our results suggest that a significant share of the gains from this type of

\footnotetext{
${ }^{7}$ Indeed, scientists have recently invested heavily in developing new seed varieties that are tolerant to various weather stresses. These investments include flood-tolerance in rice (Xu et al., 2006; Hattori et al.,
} 
technological progress will come from crowd-in effects where farmers are induced to adopt better agricultural practices and other modern inputs.

This paper is the first to consider how improved technology can help close the gap between recommended and actual cultivation practices and input use by smallholder farmers. In particular, farmers fail to adopt improved practices and use few inputs because existing seed varieties are not well-suited to their local conditions. Technological innovations that improve seed varieties and make them better-adapted to local conditions help solve part of the puzzle of inferior cultivation practices and low input use in developing country agriculture.

In addition, our paper presents a new solution to the problem of uninsured risk in developing country agriculture. Donovan (2014) uses a general equilibrium model to show that uninsured risk explains low intermediate input use in developing countries. As a result, uninsured risk contributes significantly to cross-country differences in agricultural productivity. The leading proposed solution is the reduction of exposure to risk through weather insurance, particularly index-based insurance. Empirical results indeed support the proposition that reducing agricultural risk with weather insurance can lead to significant increases in agricultural investment (Mobarak and Rosenzweig, 2012; Cole, Giné, and Vickery, 2013; Karlan et al., 2014; Elabed and Carter, 2014). The practical issue that has arisen, however, has been the repeated considerable difficulties with the uptake of insurance without high subsidies (Giné, Townsend, and Vickery, 2008; Mobarak and Rosenzweig, 2012; Cole et al., 2013; Dercon et al., 2014; Karlan et al., 2014). The literature points to several reasons for this, including high basis risk with index-based insurance, lack of trust in the provider, high loading cost, credit constraints, and insufficient understanding of the concept of insurance (Giné, Townsend, and Vickery, 2008; Cole et al., 2013; Cai, de Janvry, and Sadoulet, 2015). Our results suggest that better technology can itself be an effective way of inducing factor deepening and adoption of improved cultivation practices.

Finally, our results make a contribution to the literature on possible adaptations to climate change. Simulation evidence suggests that the risk of weather extremes - including severe flooding — will become higher as a consequence of climate shocks (Milly et al., 2002; Hirabayashi et al., 2013). Our results indicate that new technologies that increase resilience to these events not only represent a potential protection from climate shocks, they also create benefits by causing productivity gains during normal years.

The rest of this paper is organized as follows. Section 2 develops a basic farm household model that clarifies the main mechanisms through which technological change leads to factor deepening. In section 3 we outline the experimental design and the data collection. Section 2009), drought tolerance in rice and maize (Capell, Bassie, and Christou, 2004; Karaba et al., 2007; Nelson et al., 2007), and cold tolerance in rice (Fujino et al., 2008). 
4 presents results, while section 5 focuses on mechanisms that could potentially explain these results. Section 6 concludes.

\section{A Basic model of crowd-in due to technological change}

In this section we develop a farm household model of optimal choices with production uncertainty and technological change. We first set up a general model and then apply it to the specific case of the technology in our experiment. Most importantly, the model clarifies the three mechanisms through which introducing this new technology can change input use: an expected income effect, a downside risk effect, and a marginal productivity effect. We use this decomposition when interpreting our empirical results.

\subsection{Optimal choice of inputs and savings}

The model has two periods. Investment and savings decisions are made in the first period and output is realized in the second period. ${ }^{8}$ We assume that the farmer holds an exogenously determined amount of rice in the first period denoted as $h$. The farmer chooses between consuming $c$, saving an amount $s$ for the next period, and selling the remainder immediately. The farmer can spend on a continuous amount of input $x$ at a cost of $r$. Non-farm income is denoted as $w$. The discount factor is $\delta$.

The state of nature $\theta$ is revealed in the second period after the crop has been planted. In practice, $\theta$ can take several values where each corresponds to a different level of flood severity. Consumption also occurs in the second period and is denoted as $c_{1}$.

Introducing a new seed variety results in a change in the production technology. We denote $\phi$ as the amount of the new seed used. Usage of new seed is exogenous, matching the randomization in our experiment. The production function is $f(x, \phi ; \theta)$, with non-negative first derivatives, $f_{x} \geq 0$ and $f_{\phi} \geq 0, \forall \theta$.

The farmer's maximization problem is

$$
\max _{c, c_{1}, x, s} U=u(c)+\delta E u\left(c_{1}\right)
$$

\footnotetext{
${ }^{8}$ In reality the decision making process of the farm household occurs in three periods. The savings decision is made after harvest, the input decision is made at or near the time of the next planting, and the harvest is realized at the end of the growing season. We simplify the model by assuming that the first two events occur during the same period.
} 
subject to

$$
\begin{aligned}
c & \leq w-r x+h-s \\
c_{1} & \leq w+f(x, \phi ; \theta)+s \\
s & \leq h, x \geq 0, s \geq 0 .
\end{aligned}
$$

Assuming that the constraints on consumption bind with equality, the two first order conditions for $x$ and $s$ are

$$
\begin{aligned}
r u^{\prime}(c) & =\delta E\left[u^{\prime}\left(c_{1}\right) f_{x}\right] \\
u^{\prime}(c) & =\delta E u^{\prime}\left(c_{1}\right),
\end{aligned}
$$

where the expectation is taken over the states of nature $\theta$. Both savings and input use are chosen such that the expected marginal benefits in the future period are equal to the marginal cost in terms of foregone consumption in the present.

The impact of the new techology on input use is equal to

$$
\frac{\partial x}{\partial \phi}=\delta \frac{E f_{\phi} E\left[u^{\prime \prime}\left(c_{1}\right)\left(U_{x s}-U_{s s} f_{x}\right)\right]+E\left[u^{\prime \prime}\left(c_{1}\right)\left(U_{x s}-U_{s s} f_{x}\right)\left(f_{\phi}-E f_{\phi}\right)\right]-U_{s s} E\left[u^{\prime}\left(c_{1}\right) f_{\phi x}\right]}{U_{x x} U_{s s}-U_{x s}^{2}}
$$

where $f_{\phi}$ and $f_{\phi x}$ are the marginal effects of using technology $\phi$ on the level of production and the marginal productivity of input $x$, respectively, and $U_{x s}, U_{s s}$, and $U_{x x}$ are the second order derivatives of the objective function with respect to $x$ and $s$. The second-order conditions for maximization require $U_{s s}<0, U_{x x}<0$ and $U_{x x} U_{s s}-U_{x s}^{2}>0$. As savings and input use are substitute instruments to transfer rice to the second period, the cross-partial derivative $U_{x s}=r u^{\prime \prime}(c)+\delta E\left[u^{\prime \prime}\left(c_{1}\right) f_{x}\right]<0$.

Equation (4) shows three effects of the new technology on input use. The first term is the "expected income" effect due to raising expected production by $E f_{\phi}$. The second term is a pure "risk" effect due to the differential benefit of the technology across states of nature. The third term is a "marginal productivity" effect where the technology directly affects the marginal product of the input. Note that the first two terms represent "insurance effects" in that they only affect the risk averse farmers, while the third term will take place even with risk neutral households. ${ }^{9}$

\footnotetext{
${ }^{9}$ Of course, a risk neutral farmer has no incentive to save any output for the second period. In this case the model collapses to a univariate optimization where $s=0$.
} 
The expected income effect can be simplified to:

$$
E f_{\phi} u^{\prime \prime}(c) E\left[R u^{\prime}\left(c_{1}\right)\left(f_{x}-r\right)\right]
$$

where $R$ is the coefficient of absolute risk aversion in the second period. From (2) and (3), $E\left[u^{\prime}\left(c_{1}\right) f_{x}\right]=r E u^{\prime}\left(c_{1}\right)$, showing that the income effect is null when utility exhibits constant absolute risk aversion, and is positive with decreasing absolute risk aversion. The intuition is that an expected increase in second period income due to the new technology reduces the marginal utility of increased production and of savings in similar orders of magnitude, and hence has either a null or a small positive effect on input use.

Similarly, the risk effect can be simplified to:

$$
U_{s s} E\left[R u^{\prime}\left(c_{1}\right)\left(f_{\phi}-E f_{\phi}\right)\left(f_{x}-r\right)\right]+\delta E\left[R u^{\prime}\left(c_{1}\right)\left(f_{x}-r\right)\right] E\left[R u^{\prime}\left(c_{1}\right)\left(f_{\phi}-E f_{\phi}\right)\right]
$$

Under constant absolute risk aversion, the second term is null, and the first term is proportional to the covariance between increased production $\left(f_{\phi}\right)$ and the marginal value of an additional unit of input $\left(u^{\prime}\left(c_{1}\right) f_{x}\right)$. The risk effect is positive for technologies that increase production in states of nature where the marginal value of the input is low and thus the loss to the farmer from investing in the input is large. The intuition for this is that investment in the input that turns out to be unproductive is less painful to the farmer because the technology increases production, thus partially stabilizing consumption. Importantly, one can show that this risk effect is strictly increasing with the coefficient of absolute risk aversion. ${ }^{10}$

The response of savings to the new technology can be written:

$$
\frac{\partial s}{\partial \phi}=-\delta \frac{E\left[u^{\prime \prime}\left(c_{1}\right) f_{\phi}\right]}{U_{s s}}-\frac{U_{s x}}{U_{s s}} \frac{\partial x}{\partial \phi}
$$

The second term shows an effect that is opposite and proportional to the effect on input use, that directly comes from their substitute roles in moving income to the second period. The first term represents a decrease in savings due to the expected increase in income in the second period (even without any increase in input). This term contains an expected income effect $E u^{\prime \prime}\left(c_{1}\right) E f_{\phi}$ and a risk effect $E\left[R u^{\prime}\left(c_{1}\right)\left(f_{\phi}-E f_{\phi}\right)\right]$. The expected income effect is negative. The risk effect is also negative if the technology increases production more in states with lower consumption, i.e., has any risk-reducing property. The intuition for this effect is that by increasing the expected level of production in the second period, the technology crowds out savings, especially for more risk averse farmers.

\footnotetext{
${ }^{10}$ One immediate implication is that a technology that increases productivity more during good years could have the opposite effect on input use. The reason for this is that investing in the input actually increases the variance of consumption.
} 
In the particular case of the technology we study, results from both experimental plots and the first year of our experiment confirm that Swarna-Sub1 is indistinguishable from Swarna when flooding does not occur. Combining this with the fact that more severe floods lead to lower production and thus lower consumption delivers the prediction that the increase in production from the technology $\left(f_{\phi}\right)$ occurs in states where the marginal utility of consumption $\left(u^{\prime}\left(c_{1}\right)\right)$ is large. ${ }^{11}$ Assuming that the marginal product of the input is also lower during more severe flooding, the covariance term in equation (6) is predicted to be negative, making the overall risk effect positive. Thus, an important prediction from the model is that the better technology leads to an increase in the quantity of the input because it reduces the marginal damage - in terms of lost consumption - that resulted from investing in an input that turned out to be unproductive.

The marginal productivity effect is an entirely different channel through which the innovation could lead to factor deepening. Little is known empirically about the sign or size of the term $f_{x \phi}$. As equation (4) highlights, Swarna-Sub1 will increase input use if it raises the marginal product of the input, particularly in states where the marginal utility of consumption is high. As an example, if Swarna-Sub1 is a technical complement to fertilizer, then even farmers with low levels of risk aversion will use more fertilizer.

We provide some non experimental evidence distinguishing between these two explanations of our results in the empirical analysis. For this, we take advantage of the fact that treatment farmers continue to cultivate some plots with current non-flood-tolerant seed varieties even after gaining access to Swarna-Sub1. Any technical relationship in the production function between inputs and Swarna-Sub1 is eliminated on these plots. Put differently, the marginal productivity effect on these plots is plausibly zero. However, the risk effect still operates because it is a function of the overall increase in production induced by Swarna-Sub1, making a yield effect on these plots potentially positive.

\subsection{Introducing credit}

We do not formally model the demand for agricultural credit. Instead, we discuss how introducing the new technology can affect utilization of agricultural credit in a credit environment similar to the one faced by farmers in our sample.

There are two important characteristics of the credit market for farmers in our sample. First, local agricultural cooperative societies are the most popular source of credit. $45 \%$ of loans during year one of the experiment came from cooperative societies. Since cooperatives have limited resources, borrowing constraints are likely to be relevant. Second, limited

\footnotetext{
${ }^{11}$ Implicit in this statement about the correlation between the productivity increase and the marginal utility of consumption is an assumption of imperfect consumption smoothing, as in Townsend (1994).
} 
liability is a feature of these loans. In particular, $40 \%$ of loans from year one were renegotiated or had liability fully waived. ${ }^{12}$

Credit could therefore be realistically introduced into the model by allowing both borrowing constraints and limited liability. Specifically, the household borrows an amount $b$, where an exogenous borrowing constraint forces $b \leq \bar{b}$. Assuming that $\gamma$ is the degree of limited liability, the household must pay back $(1-\gamma)(1+v) b$ during the second period, where $v$ is the interest rate. Since loans are most likely to be forgiven after flooding, it is plausible to assume that $\gamma=0$ in the event that flooding does not occur.

Under this setup, there are two plausible mechanisms which could explain how introducing the new technology will influence credit usage. First, by increasing production during the flood state, the technology increases consumption, thus decreasing the marginal utility of consumption. This makes it less painful to have liabilities and therefore increases demand for credit. This effect becomes less relevant as limited liability increases because it effectively acts as insurance by further increasing consumption during flooding. Second, making production less risky could induce cooperatives to make more credit available to treatment farmers - an increase in $\bar{b}$. This supply effect would increase credit utilization as long as credit constraints were binding prior to introduction of the technology. ${ }^{13}$

While the frequency of limited liability in our data suggests that the credit supply mechanism is most relevant, our empirical analysis cannot distinguish between these two mechanisms. Also, increased uptake of credit could play a role in decreasing savings of stored rice: additional credit could further crowd in input use at planting, which increases output and decreases the need for precautionary savings (Fulford, 2013).

\section{$3 \quad$ Experimental design and data}

In this section we present the details of the experimental design and sampling. In addition, we outline the timing of data collection and present summary statistics on both village and household characteristics.

\footnotetext{
${ }^{12}$ Loans from agricultural cooperative societies in areas where heavy flooding occurred were nearly twice as likely to have their terms changed compared to loans from other sources. The probability of renegotiation is also increasing in the duration of flooding.

${ }^{13}$ Boucher, Carter, and Guirkinger (2008) show theoretically that uninsured risk can induce lenders to offer loan terms that effectively crowd out a large share of the credit market. Carter, Galarza, and Boucher (2007) use simulations to suggest that weather insurance can indeed crowd in credit supply in rural Peru.
} 


\subsection{Experimental design}

Our sample is drawn from villages in flood-prone areas of the Bhadrak and Balasore districts of northern Odisha. This area is suitable for the study because flood risk is high, Swarna is widely grown, and Swarna-Sub1 was still unavailable to farmers in May 2011 when the project was initiated. The villages were identified from two sources. In Bhadrak, satellite imagery was matched to a GIS database of villages to identify villages that were affected by flooding. ${ }^{14}$ A random subset of 64 affected villages was selected for inclusion in the study. In Balasore, we used a list of flood-prone villages established by our local NGO partner to randomly select 64 villages. ${ }^{15}$ Figure 1 displays a map of the study area and the villages included. As is seen in the map, almost all of the study villages are in low-lying coastal areas.

We first randomly divided the 128 sample villages into treatment and control groups. This village-level randomization was stratified by blocks, which are administrative units that consist of 100-200 villages. The 128 sample villages are spread across 8 blocks. A local government official was then visited in all villages to generate a list of 25 farmers using Swarna and affected by flooding. Using this list, 5 farmers were randomly selected in each of the 64 treatment villages to receive minikits containing five kilograms of SwarnaSub1 seeds. ${ }^{16}$ The seeds were delivered in June 2011, which is right before planting. Our comparison group consists of ten randomly selected non-recipients in treatment villages and five randomly selected farmers in the 64 control villages. ${ }^{17}$

In addition to the minikit, treatment farmers were provided with a two-page information sheet on Swarna-Sub1. The information sheet had two important components. First, we included pictures from farmer-managed trials showing the clear productivity gains of SwarnaSub1 after flooding. Second, the information sheet conveyed that other than flood tolerance, Swarna-Sub1 is identical to Swarna. Importantly, the sheet did not suggest any management practices such as how to plant the field or how much fertilizer to use. Instead, farmers were informed that Swarna-Sub1 can be managed exactly like Swarna.

Importantly, several villages in the sample were affected by heavy flooding during September 2011. Approximately $40 \%$ of plots in our sample were fully submerged - and detectable with satellite images - during the flood. While inundation occurred in both districts of the

\footnotetext{
${ }^{14}$ We used RADARSAT images (100m resolution) from 2008 to identify villages affected by flooding.

${ }^{15}$ The satellite imagery of historic floods was not available at the time of village selection.

${ }^{16}$ Five kilograms of seed is sufficient to cultivate 0.1 to 0.2 hectares, or approximately $10-20 \%$ of average cultivated area. This is the standard minikit size for cereal crops in India.

${ }^{17}$ We show in Table A9 that our main outcomes are not significantly different between non-recipients in treatment and control farmers. Thus, the technology did not generate significant within-village spillover effects. Therefore, we retain both sets of non-recipient farmers in all specifications.
} 
sample, the heaviest flooding occurred in the southernmost district of Bhadrak.

The implementing NGO did not provide additional seeds to treatment farmers after year one. Given that Swarna-Sub1 seeds were not available on the market, the only way to continue using the variety was to save a portion of the year one harvest as seeds for cultivation during year two.

\subsection{Data collection}

Our first follow-up survey was conducted in March 2012 after the first year's crop was harvested. A total of 1,248 farmers were reached, achieving a response rate of $97.7 \% .{ }^{18}$ Compliance with the treatment during the first year was near universal. Only 2 out of the 320 treatment farmers declined to receive the minikit and cultivate it on their land. Treatment farmers cultivated approximately 14\% of their land with Swarna-Sub1.

The second follow-up survey was carried out one year later after the growing season for year two. A total of 1,237 of the farmers surveyed during 2012 were reached again during this survey. Important outcomes of interest are area cultivated, farm-level information on inputs, allocation of output across uses, and credit utilization. In addition, a plot-level module on seed variety choice, planting methods, and production was administered.

Compliance with the treatment during the second year — defined as continued cultivation of Swarna-Sub1 — was high. $76 \%$ of minikit recipients cultivated the technology during year two. ${ }^{19}$ The average number of plots sown with Swarna-Sub1 amongst minikit recipients was 1.5. Average land area cultivated with Swarna-Sub1 was 0.33 hectares, or approximately a third of average landholdings. Conversely, only $10.1 \%$ of control farmers cultivated SwarnaSub1 during year two. We show in Table A1 that this was a direct result of seed transfers from original recipients: $13.3 \%$ of control farmers cultivated Swarna-Sub1 in treatment villages and only $3.3 \%$ did so in control villages. Given the low levels of non-compliance across the two years of the study, we take a conservative approach and report intention-to-treat (ITT) results throughout the paper.

\footnotetext{
${ }^{18}$ This small level of attrition is balanced across treatment and control. Enumerators were not able to contact farmers in one control village due to disagreement with local village leaders about participation in the study. The results reported are for the remaining 127 villages.

${ }^{19}$ The most common reason for disadoption was crop loss during year one. Swarna-Sub1 is not suitable for low areas where water remains stagnant for more than two weeks after flooding (Singh, Mackill, and Ismail, 2011). Swarna-Sub1 that was planted in these areas during year one was lost.
} 


\subsection{Summary statistics}

Villages in the sample are fairly representative of the low-lying villages in the flood-prone states of Bihar, Odisha, and West Bengal. Table 1 shows village characteristics from the 2001 census. ${ }^{20}$ With the exception of village size, the sample villages are roughly similar to all villages in low-lying areas of the three states.

Turning to the household-level data from our sample, Panel A of Table 2 reports summary statistics of variables that are likely predetermined, but were collected during the first followup survey. Most importantly, treatment and control households look similar on most predetermined characteristics. Farms in the sample are small. Average landholdings are less than one hectare. While electricity is fairly widespread, few households have access to piped water. Most households rely on either village or private tubewells for water. Approximately $56 \%$ of households have Below the Poverty Line (BPL) cards, which give them access to government supports such as a monthly allotment of subsidized rice. Panel B of the table shows some characteristics of the plots held by farmers in our sample. Farmers cultivate an average of around 3.5 plots and a third of those are in lower-lying areas. On average, farmers report that a plot was flooded for around 5.5 to 6 days during the first year.

\section{Results}

This section presents results supporting the argument that improved technology modernizes agriculture by increasing the use of modern agricultural practices and inputs. We first outline the estimation approach and then present the main results on cultivation practices, fertilizer use, rice storage, and credit. We then show that the technology leads to substantial gains in land productivity - even in year two when there was no flooding. We then benchmark the year two productivity gains due to crowd-in against the expected technical gains that arise from flood tolerance. Finally, we also consider whether the additional investments that were induced translate into profitability gains rather than just productivity gains.

\subsection{Estimation Approach}

Our main approach is to use the random distribution of Swarna-Sub1 seeds to explain management choices at both the farm and plot level. The baseline specification is therefore

$$
y_{i v b}=\beta_{0}+\beta_{1} \text { treatment }_{i v b}+\alpha_{b}+\varepsilon_{i v b},
$$

\footnotetext{
${ }^{20}$ Villages in the other three states were included if the elevation was below 56 meters, the maximum elevation in our sample of villages.
} 
where $y_{i v b}$ is an outcome observed for farmer $i$ in village $v$ and block $b$, and $\alpha_{b}$ is a fixed effect for the block, which was a stratification variable for the village-level randomization. The error term is clustered at the village level since this corresponds to the first tier of randomization. We continue to use the farmer-level treatment indicator when outcomes are observed at the plot level. The estimate of $\beta_{1}$ in the plot-level regressions therefore represents an average effect across all plots, not just the plots cultivated with Swarna-Sub1.

This intention to treat (ITT) estimate of $\beta_{1}$ would obviously be attenuated if there were either significant disadoption by minikit recipients or adoption by non-recipients. As we noted above, compliance was nearly $100 \%$ in the first year of the study. Given the small amount of non-compliance during year two, instrumental variables estimates of treatment on the treated (TOT) effects would be larger by a factor of approximately 1.5. We report the ITT estimates as they carry the most policy relevance when dissemination of the new technology naturally leads to some disadoption due to imperfect targeting.

We only use the variation generated by the experiment by including only the treatment indicator and the strata (block) fixed effects in our main specifications. However, we show in Tables A2 to A6 that our main results are unaffected by controlling for household covariates. Finally, when our data allow, we estimate our main specifications separately for years one and two.

\subsection{Cultivation practices and inputs}

The improved technology led to a small expansion in cultivated area. Column 1 of Table 3 shows that access to Swarna-Sub1 led to an immediate increase in area of 0.07 hectares or around a $9 \%$ increase. Panel B shows that this effect rose only slightly during year two. Overall, the result suggests that some land is left uncultivated due to flooding risk and that improved technologies that address this brings this land into production. Also, we show in Table A7 that treatment farmers were significantly less likely to take land out of production (fallowing) during the second year, in particular plots that are low-lying and considered to be lower quality. The decreased likelihood of taking these flood-prone lands out of production partly explains the observed effects on cultivated area during year two. Table A8 shows that the area effect is driven by cultivation of additional plots, not increased area of existing plots.

While Swarna is the most popular rice variety grown in the sample region, farmers often use local "traditional" varieties that are not considered modern and high-yielding. These varieties have a high capacity to survive during flooding due to their ability to rapidly 
elongate when submerged (Voesenek and Bailey-Serres, 2009). ${ }^{21}$ We show two pieces of evidence in the online appendix that flooding risk is one of the reasons this traditional technology is still used. First, when asked, farmers directly state that one of the main reasons for adopting these varieties is their tolerance to flooding (see Figure A1). Second in Figure A2 we show that these varieties had higher survival rates in heavily flooded areas during year one.

Not surprisingly, column 3 of Table 3 shows that plots cultivated by treatment farmers were less likely to be sown with Swarna by 15.7 percentage points and 10.1 percentage points in years one and two, respectively. More interestingly, there was an immediate reduction in the use of traditional varieties by 2.9 percentage points (14\%) during year one and 4.1 percentage points (or 14.6\%) during year two (column 4). Thus, the crowding out of traditional varieties is one of the channels through which the innovation affects output.

In addition to modernization of seed varieties, the technology also led to a modernization of planting methodology. Column 5 shows that farmers given access to the improved technology were less likely to opt for the cheaper, less productive, and traditional planting method of manually broadcasting seeds. Instead, treatment farmers were more likely to use the more labor intensive method of manually transplanting seedlings. ${ }^{22}$ Panel A shows that plots cultivated by treatment farmers were 2.2 percentage points (around $22 \%$ ) less likely to be sown using the broadcasting method during year 1. During year 2, this effect rose to 6.3 percentage points, or around $33 \%$.

Improved technology also induced greater fertilizer use during year two. ${ }^{23}$ Column 1 of Table 4 shows that conditional on cultivated area, total fertilizer expenditures rose by 397 Rs or $10.5 \%$ for treatment farmers. Columns 2 through 5 show that this increase in fertilizer expenditure is almost entirely concentrated on phosphate (DAP) and potassium (MOP) fertilizers. We show in Figure A3 that phosphate and potassium fertilizers are generally used earlier in the growing season. ${ }^{24}$ Combining these two facts, the improved technology

\footnotetext{
${ }^{21}$ We have yet to distinguish between flash flooding, where Swarna-Sub1 performs well, and stagnant water accumulation. Flash flood areas are those where flooding occurs and water recedes after a period of one day to around two weeks. Stagnant water areas are those where water remains partially submerging the crop even after floodwaters recede. Our findings in Dar et al. (2013) and other research (i.e. Singh, Mackill, and Ismail (2011)) show that Swarna-Sub1 does not tolerate stress due to stagnant water of more than approximately 15 days.

${ }^{22}$ Transplanting involves raising seedlings on a small portion of land, pulling and bundling the seedlings after approximately three weeks, and planting the seedlings manually in the main field. While broadcasting is a popular planting technique in flood-prone areas due to a lower labor requirement, increased competition from weeds reduces yields (Khush, 1997; Rao et al., 2007).

${ }^{23}$ Our first follow-up survey only included fertilizer use on the Swarna-Sub1 plot of treatment farmers and the largest Swarna plot of control farmers. Due to plot selection issues, we do not use these data to estimate effects on fertilizer usage.

${ }^{24}$ This is also consistent with basic agronomic recommendations based on the functions of the different
} 
resulted in increased fertilizer use only for fertilizers that are used earlier in the growing season when the risk of exposure to flooding is highest. This provides further evidence that this technology led to additional investment near planting and helped close the gap between actual and recommended fertilizer application. ${ }^{25}$

\subsection{Storage and credit}

Farmers in the sample store large amounts of rice after each harvest relative to their annual consumption. The average total rice harvest amongst cultivators in our sample was 2,945 kg. An average of $1,711 \mathrm{~kg}$ of the harvest was consumed or set aside for future consumption. ${ }^{26}$ This amount is enough to feed roughly 11 adults for a year. ${ }^{27}$ Average household size in the villages in our sample is 5.3 persons. While we acknowledge that stored rice is a liquid asset that can be sold upon family need, one plausible explanation of this large amount of rice storage is the need to insure against future consumption variability.

Farmers receiving Swarna-Sub1 store a smaller share of their harvest for future consumption. Column 1 in Table 5 shows that after year one, treatment farmers stored 2.6 percentage points less output for consumption. While this effect is not quite statistically significant, Panel B shows that the effect after year two rises to 5 percentage points and is statistically significant. $^{28}$ The magnitude of the effect is not trivial. It amounts to approximately 150 kilograms, or enough to meet the consumption needs of one household member for the entire year. Column 2 of Panel B shows that the storage effect during year two is concentrated amongst households that do not hold Below the Poverty Line (BPL) cards. BPL cards serve as consumption insurance because they entitle households to purchase 30 kilograms of rice per month - an amount that is enough to feed approximately two adults - at highly subsidized rates. ${ }^{29}$ This additional heterogeneity is consistent with the technology decreasing nutrients. In particular, phosphorous (DAP) and potassium (MOP) contribute mostly to soil conditioning and root development, and are applied early in the growing season. In contrast, nitrogen - in the form of urea - contributes to healthy plant and leaf development and therefore is mostly applied later in the season after the plant is more fully developed and leaf growth is occuring.

${ }^{25}$ Fertilizer application in our sample is still below recommendations in spite of high subsidies. An approximate recommendation for our sample area is a per-hectare application of $80 \mathrm{~kg}$ of nitrogen $(\mathrm{N}), 40$ kilograms of phosphorous (P), and 40 kilograms of potassium $(\mathrm{K})$. The median farmer in the control group during year two applied $57.8 \mathrm{~kg}$ of nitrogen, $34 \mathrm{~kg}$ of phosphorous, and $15.5 \mathrm{~kg}$ of potassium for each hectare of land cultivated. In contrast, the median farmer in the treatment group applied $59.7 \mathrm{~kg}$ of nitrogen, 39.1 $\mathrm{kg}$ of phosphorous, and $18.3 \mathrm{~kg}$ of potassium.

${ }^{26}$ Since our survey was conducted shortly after the harvest and post-harvest production practices, most of the amount indicated for consumption had yet to be consumed at the time of the survey.

${ }^{27}$ This calculation is based on an average annual consumption in rural Odisha of 158 kilograms per capita per year, as reported in the 64th round of the National Sample Survey.

${ }^{28} \mathrm{~A}$ similar regression where the dependent variable is the share of rice sold delivers a coefficient estimate of .047. Thus, much of the output that was not stored for consumption was instead sold.

${ }^{29}$ The price of BPL rice is 1-2 Rupees per kilogram while the market price of similar rice is 20 Rupees or 
the need to use storage as a form of consumption insurance.

In addition to reducing storage rates, improved technology that reduces downside risk increases the uptake of agricultural credit. Columns 3-5 of Table 5 focus on binary indicators of household access to credit. Column 3 shows that credit uptake increased by 6.3 percentage points immediately during year 1 , but the effect is not statistically significant at conventional levels. Given average credit uptake of $43 \%$, this effect amounts to about a $15 \%$ increase. Average uptake of new loans across the entire sample was much smaller (19\%) during year two. However, Column 3 in Panel B shows that treatment farmers were 6.8 percentage points more likely to take out a new loan during the time between planting and harvesting for year two. This amounts to a meaningful 36\% increase in credit uptake. Columns 4 and 5 show that a large portion of the effect is driven by loans originating from agricultural cooperatives.

In contrast to inputs, the results on rice storage and credit uptake are unlikely to be explained by shifts in the marginal productivity of inputs. Rather, storage offers insurance against low or zero production during flooding. By increasing the overall level of production during flooding, the technology substitutes directly for storage. Utilization of agricultural credit increases either due to a demand effect where the increase in expected production in the future makes borrowing more desirable, or a supply effect where credit constraints are a function of the borrower's expected production.

\subsection{Effects on productivity}

The results indicate that improved technology induces the adoption of several other modern inputs and management practices. A natural next question is to ask how these changes translate into productivity gains.

There is a noticeable increase in yield for plots cultivated by farmers with access to Swarna-Sub1. Figure 2 displays the estimated kernel densities of yield by treatment status for both years of the study. Focusing on year one, the severe flooding in part of the sample is apparent as there is a significant mass of the distribution at low yields. However, there is also a clear rightwards shift in the distribution of yield for treatment farmers. This effect is a combination of the purely technical gains in flooded areas with the gains due to the small crowd-in effects reported above.

Panel B shows that there is a clear rightwards shift in the distribution for treatment farmers during year two when flooding did not occur. This effect occurs throughout the distribution of yield, suggesting that it is not concentrated on the lowest or highest productivity farmers.

higher. 
The regression results in Table 6 are consistent with the graphical evidence. Column 1 shows that the technology led to an increase in yield during year one of 315 kilograms per hectare, or around 14\%. In year two, when flooding did not occur and all productivity gains are due to crowd-in, treatment farmers harvested an average of 283 kilograms more per hectare cultivated. This translates into a $10 \%$ increase in productivity.

As a method of investigating whether the crowd-in effect is a channel through which improved technology affects productivity, we sequentially add our main outcome measures as regressors to the yield equation. Adding these endogenous outcomes as controls should attenuate the reduced form productivity effect if the effect is partly operating through these channels. ${ }^{30}$ Of course, the coefficients on the endogenous outcome variables represent merely correlations and cannot be interpreted causally.

The conditional productivity effect is substantially lower than the unconditional effect. Columns 3-5 of Table 6 show that accounting for the observed changes in production practices substantially attenuates the productivity effect. In addition, the goodness of fit of the regression approximately doubles. Therefore, the crowd-in effect is an important determinant of the overall productivity effect of the technology.

How large are these indirect effects of the new technology? We next benchmark this crowd-in effect against the expected yield gains from controlled laboratory experiments on agricultural experiment stations. Agronomic benefits reported by experimental stations are importantly measured while input use is held constant and thus the only advantage of the improved technology occurs through its technical superiority. Singh, Mackill, and Ismail (2009) show that the maximum yield benefit of Swarna-Sub1 under 12 days of flooding is approximately 2 tons per hectare. In addition, the absolute magnitude of the yield benefit in farm-trials declines as flood severity worsens beyond 12 days.

To generate the probability that a field in our sample would be flooded during the wet season, we use satellite imagery from past flooding. We used imagery of all flooding in the two districts from 2002-2008 and 2011-2014 to identify areas affected by flooding. ${ }^{31}$ We overlaid these flood areas with the GIS centroid of 1,123 plots cultivated by farmers in our sample. These GIS coordinates were collected for the Swarna-Sub1 plot of treatment farmers and the largest Swarna plot of control farmers. Figure 3 shows the distribution of flooding for these plots across the 11 years for which we had satellite imagery. Notably, the most

\footnotetext{
${ }^{30}$ This approach has been used to investigate the channels through which education affects voting (Milligan, Moretti, and Oreopoulos, 2004) and the channels through which early-life rainfall shocks affect outcomes later in life (Maccini and Yang, 2009). In our case the reduced form treatment effect that remains after conditioning on inputs can be thought of as a measure of TFP.

${ }^{31}$ These data come from the MODIS satellite and have a resolution of $250 \mathrm{M}$. The data were downloaded at http://floodobservatory.colorado.edu/Modis.html. A more detailed description of the data is available on this website.
} 
severe flood year was 2011, the first year of the experiment. Approximately $40 \%$ of plots were detected as flooded using the satellite images during 2011. Also, there was almost no flooding during the following year: only $2 \%$ of plots were detected as flood-affected during 2012 .

The overall average probability of flooding across the 11 years is 0.19 , which is the horizontal line displayed in Figure 3. This average probability is similar across the Swarna and Swarna-Sub1 plots. Combining this with the estimated yield advantage of 2 tons per hectare during flooding, $380 \mathrm{~kg}$ per hectare is a very conservative upper bound estimate of the expected technological gains due to agronomy. Thus, we estimate that the 283 kilogram per hectare gain due to crowd in effects represents no less than $43 \%$ of the overall gains from the innovation.

An implication of this finding is that estimated returns of new technologies that do

not account for how farmers re-optimize their decisions will significantly understate the gains from new technologies. In addition, this result further demonstrates the value of using field experiments to measure the impacts of new agricultural technologies. Studies on experimental plots that don't account for re-optimization of farmers will not deliver the true causal effects of new technologies.

Including these productivity effects, we have shown that the flood-tolerant rice variety has significant impacts on several outcomes of interest. However, we have thus far only considered the outcomes individually and have not adjusted the p-values for multiple inference. In Table A10 we show all regression results for the 20 agricultural outcomes measured by our second year follow-up survey. More importantly, we show that adjusting p-values for multiple inference by controlling the false discovery rate does not significantly alter the conclusions of our hypothesis tests (Benjamini, Krieger, and Yekutieli, 2006; Anderson, 2008).

\subsection{Are additional investments profitable?}

We have shown that increased investment is an important channel through which improved agricultural technologies lead to substantial gains in productivity. In particular, average yield of farmers given access to flood-tolerant rice increases by around $283 \mathrm{~kg}$ per hectare (Table 6). This amounts to an increase in revenue per hectare of 2,969 Rs when applying the average output price from our survey of $10.5 \mathrm{Rs}$ per $\mathrm{kg}$. However, the increased investments that drive this increase, such as using more fertilizer or changing planting techniques, are indeed costly. Therefore, the gains in profitability are undoubtedly lower than the measured productivity gains.

Additional calculations suggest that the incremental costs associated with the observed 
management changes represent less than half of the gains in revenue. We estimate that the cost increase resulting from the observed changes in management is around 1,103 Rs per hectare. This represents only $37 \%$ of the estimated revenue gains and therefore suggests that the technology does lead to gains in profitability. We explain the details of this calculation in the remainder of this section.

Fertilizer use: We rely directly on our estimates in Column 1 of Table 4 to generate an increase in fertilizer cost of 397 Rs. Given that farmers cultivate an average of one hectare, we also use this value as the increase in fertilizer costs per hectare.

Labor for fertilizer: Our first follow-up survey included information on total labor use including family labor - for physically applying fertilizers. We calculate that on average, for each $100 \mathrm{~kg}$ of fertilizer applied, a total of 6 person days are required. Applying this number to the increase in fertilizer usage in kilograms rather than expenditures, we obtain an increase in labor demand of 1.48 days. Valuing all labor at the average wage of 161 Rs per day, this amounts to an increase in labor costs of 238 Rs per hectare.

Labor for planting: Our first follow-up survey also included information on labor used for sowing for a single plot of each respondent. We simply compare average labor costs per hectare between plots that were planted using the broadcasting and transplanting methods. A caveat of this exercise is that the comparison is clearly non-experimental. ${ }^{32}$ We find that labor costs for transplanting are larger by 5,670 Rs per hectare - an approximate three fold increase relative to the broadcasting method. Multiplying this value by the decrease in the probability of broadcasting of .063 , we obtain an increase in average planting costs per hectare of 357 Rs.

Loan interest: Our second follow-up survey asked the annual interest rate for each loan. We combine this with the value of the loan to estimate annual interest costs for each farmer in the sample. ${ }^{33}$ We simply regress this value on the same set of regressors used in our main specifications. Doing this delivers an increase in annual interest costs of 82 Rs.

\footnotetext{
${ }^{32}$ It is most likely that this simple comparison of means overstates the effect of transplanting on planting costs. Farmers would be more likely to use transplanting with higher-yielding varieties that may induce more labor use at planting independently of choice of planting technique. The estimate is also conservative because one of the benefits of transplanting is reduced weed populations. Consequently, a portion of the increase in planting costs that results from transplanting is offset by reduced costs of weeding.

${ }^{33}$ This is only an estimate because our survey was carried out immediately after harvest and thus we do not measure the timing of repayment.
} 
Seed cost: Treatment farmers in our sample had no choice but to use Swarna-Sub1 from their previous harvest. The effective price of seeds in this case is their opportunity cost, which is the price that would have been obtained had the output been sold as rice instead. As we show below, farmers report an average increase in output price for Swarna-Sub1 of 0.46 Rs per kilogram. Combining this with an approximate seed rate of 62 kilograms per hectare, the additional cost of Swarna-Sub1 seeds is around 29 Rs per hectare.

\section{Mechanisms}

Our results suggest that an improved technology that decreases the downside risk of production causes farmers to re-optimize along several dimensions. While the results are consistent with our model where reducing risk is one of the important mechanisms, there are some other equally plausible explanations. In this section we consider some alternative tests to investigate whether the data are consistent with these explanations. Importantly, these tests cannot definitively point to risk as the only explanation of our findings. We are therefore cautious to interpret the findings as suggestive that only mechanisms other than risk are not entirely consistent with the data.

\subsection{Shifts in the marginal productivity of inputs}

Returning to the theoretical model, the marginal productivity effect is one of the channels through which introducing a risk-reducing seed variety could influence input use. If the new variety is a technical complement to an input like fertilizer, then the variety could naturally increase fertilizer use independent of its risk-reducing property. We attempt to rule this out as the only explanation for our results by considering plots that were cultivated by treatment farmers, but were not cultivated with Swarna-Sub1. We estimate our main effects on this sub-sample of plots. If the results are explained by how the technology itself changes the marginal productivity of these inputs, then there is no reason to observe any effects for these plots.

While the effects are smaller, the effects on productivity, broadcasting, and DAP fertilizer expenditures all persist on plots where Swarna-Sub1 was not used. Column 1 of Table 7 shows a yield effect of 173 kilograms per hectare, or approximately 6\%. Columns 2 and 3 show that there is no substitution away from other rice varieties on these plots, suggesting that any effects on inputs are not due to which varieties were grown. ${ }^{34}$ Column 4 shows that there remains a 4.2 percentage point decrease in the probability of using broadcasting by treatment

\footnotetext{
${ }^{34}$ Table A11 shows that the results are robust to controlling for variety fixed effects.
} 
farmers on the plots not cultivated with the new technology. Finally, plot-level expenditures on DAP fertilizer are higher by around 100 Rs for treatment farmers on non-Swarna-Sub1 plots (column 7). In combination, these results help to rule out the mechanism where the new technology simply increases the marginal products of inputs.

However, an important concern with this approach is the endogeneity of plot choice. If treatment farmers allocated Swarna-Sub1 to their worst lands, then the treatment-control comparison on the remaining plots would artificially favor finding effects of treatment on these outcomes. ${ }^{35}$ As the first approach to reducing these selection concerns, Table 7 includes controls for self-reported land quality, relative elevation (or slope) of plots, land ownership, and area of the plot. The main effects in the table are therefore all conditional on these potential sources of selection.

We address concern about selection on unobservables by constructing a simple simulation to assess the degree to which these results could be driven by plot-level selection. Treatment farmers cultivate on average 0.235 fewer plots with non-Swarna-Sub1 varieties. This is fairly modest since control farmers cultivate an average of 3.6 plots with these same types of varieties. We construct a simulation where we take each control farmer in the sample and randomly drop one of their plots with a probability of 0.235 . We make the simulation exercise as conservative as possible by generating a random number from the unit interval for each control farmer and dropping their lowest-yielding plot if that random number is less than 0.235. This results in a trimmed sample where 184 plots are dropped from the analysis. Importantly, trimming balances the total number of plots across treatment and control farmers in a way that can only reduce the treatment effect.

We show in Table A14 that while conservatively trimming the sample in this way decreases the main coefficients of interest, the estimates remain statistically significant at at least the $10 \%$ level. This provides suggestive evidence that the comparison of non-Swarna-Sub1 plots across treatment and control farmers is not being driven entirely by plot selection.

\subsection{Changes in mean yield rather than variance}

The technology we study decreases downside risk without affecting yield during "good years" when flooding is absent. As a result, the technology both decreases the variance in output and increases mean yield. One potential explanation of our findings is that they could be

\footnotetext{
${ }^{35}$ We show in Table A12 that the plots cultivated with Swarna-Sub1 were on average smaller, more likely to be land that was owned by the farmer rather than sharecropped and less likely to be on the lowest land in the village. However, Table A13 shows that the plots not cultivated with Swarna-Sub1 are roughly similar on these observables. A plausible explanation that reconciles these two results is that minikit recipients cultivated more plots as a result of obtaining the new technology. While those new plots were on average different than the other plots, this does not affect the remaining non-Swarna-Sub1 plots.
} 
driven by this income effect where the expectation of increased output at the end of the season changes agricultural decision-making. The ideal experiment to decompose between these two channels would involve promising compensation to control farmers in the amount equal to the gain in expected output from Swarna-Sub1. This gain in expected output depends on both the yield advantage of Swarna-Sub1 and the total land area cultivated with it. It is important to note that compensating control farmers before planting in the amount equal to the expected output gain is likely conservative because of discounting, the increased certainty of compensation relative to uncertain productivity gains in the treatment group, and the liquidity value of having additional capital before planting.

We exploit natural variation in our data to simulate an experiment where compensation is provided before planting. During the first year of the study there was spatial variation in the intensity of flooding, even within fairly small geographic areas. We use this variation to generate a measure of the flood shock (or lack thereof) that would have been equivalent to the gain in expected output caused by Swarna-Sub1. Our calculation in Section 4.4 suggested that an upper-bound estimate for the purely agronomic gain of Swarna-Sub1 was $380 \mathrm{~kg}$ per hectare. Combining this with the fact that treatment farmers cultivated an average of 0.33 hectares with Swarna-Sub1 during the second year, the required compensation to turn off the expected output channel would be equivalent to 126.7 kilograms of rice. Table A15 shows that an additional day of flood exposure during the first year caused the total production of control farmers to decrease by $90.3 \mathrm{~kg}$. Therefore, a decrease in flood exposure by 1.4 days is equivalent to the expected output gain from Swarna-Sub1. If our results are entirely driven by the mean-increasing property of the technology, then we would expect the effects of being exposed to 1.4 fewer flood days for control farmers to be equivalent to our measured effects of giving the new technology.

The results do not appear to be entirely driven by the mean-increasing property of Swarna-Sub1. Table A16 compares the main effects of the Swarna-Sub1 treatment with the effects of an equivalent flood shock in the control group — which is the farmer's areaweighted flood exposure divided by 1.4. Total fertilizer expenditure is the only outcome that decreases significantly with an additional 1.4 days of flood exposure. However, the negative effect of an additional 1.4 days of flooding is around 1/5th the size of the effect of the SwarnaSub1 treatment. While this test is imperfect because it relies on non-experimental variation, the results are mostly inconsistent with our results being driven by how the technology shifts the mean level of output. 


\subsection{Other alternative explanations}

An additional potential income effect is that cultivation of the new seed variety during year one led to a boost in agricultural income which then crowded in improved inputs and practices during the following year. Our results do not appear consistent with this explanation for two reasons. First, the fact that we observe moderate impacts immediately during year one suggests that wealth effects from crop output during year one do not entirely explain our results during year two. Second, as another piece of evidence, we use data on the total quantity of rice harvested during the first year as a measure of the wealth that would have been influenced by being treated. If increases in wealth due to the new technology led to the changes we observe during year two, then controlling for the year one harvest should attenuate our main estimates. We show in Table A17 that none of our main estimates are affected when conditioning on the year one total harvest.

Are differences in output prices responsible for our results? We collected information on prices received by variety from each farmer that sold any output after the second year of the study. The average price received for Swarna was 10.29 Rupees per kilogram and the average price received for Swarna-Sub1 was $10.76 .{ }^{36}$ This $4.6 \%$ difference in prices is statistically significant at the $5 \%$ level. Since the eating quality of the two varieties is similar (see Figure A1), this difference in prices could possibly be due to increased value of output as seed rather than grain for consumption.

There is no evidence that output prices drive the results. Descriptively, only $40 \%$ of farmers sold any rice following the second year and on average only $17 \%$ of the harvest was sold as grain for consumption, suggesting that effects of output price differences are likely to be small. We consider this possibility further by separate estimation of the main results for the subsample of farmers that did not sell any rice following the second year. ${ }^{37}$ If prices are explaining the results, then the effects of the technology should be smaller in this sub-sample. We show in Table A18 that this is not the case. This evidence is not consistent with output prices being the relevant channel for our results.

\footnotetext{
${ }^{36}$ The government's paddy procurement program set the minimum support price (MSP) for the 2012 harvest at 12.5 Rupees per kilogram. Many farmers in our sample sell instead to private traders at prices below this level.

${ }^{37} \mathrm{~A}$ problem with this approach is that the sample is being split according to an endogenous outcome. The most plausible effect of sample selection in this case is that the group of farmers selling rice are the largest and wealthiest farmers that have the most capacity to respond after having access to Swarna-Sub1. For instance, average landholdings of farmers that do not sell output are $50 \%$ less than the landholdings of those selling output. This would then work against us finding any effects in the subsample of farmers not selling output.
} 


\section{Conclusions}

This paper has shown that technological progress in agriculture can have the important effect of crowding in the use of both more productive cultivation practices and modern inputs. This suggests that lack of more productive and resilient technology can be at least a partial reason why smallholder farmers in developing countries often fail to adopt improved production practices and use few modern inputs. We have focused on new rice varieties that reduce downside risk through enhanced flood tolerance.

Additional calculations suggested that much of the gains from these new technologies come from this crowding-in effect. By inducing more use of a labor intensive planting method, increased investments in fertilizer, increased uptake of credit, and displacing traditional seed varieties, technology boosts productivity. Put differently, the absence of seed varieties that are well-adapted to local conditions causes farmers to opt for traditional low-input and low productivity cultivation strategies. Our best estimate indicates that no less than $43 \%$ of the expected gains from seed varieties that reduce downside risk can be attributed to crowd-in effects.

These results provide the first evidence on how technological progress that reduces downside risk in agriculture can modernize farming in areas where production risk is high. While the technology in our experiment has already been adopted by around 3 million farmers in India alone (Ismail et al., 2013), technological progress that makes seed varieties more tolerant to weather extremes is not unique to India. Since 2011, new rice varieties that are tolerant to either flooding, drought, or extreme cold temperatures have been released in 11 countries in South Asia and Africa alone.

These results suggest that efforts to improve technology by reducing the susceptibility of commonly used seeds to weather extremes can go a long way in increasing agricultural productivity. While the Green Revolution was successful at increasing agricultural productivity in favorable areas throughout the world, productivity in rainfed areas under weather stress remains low. Using flood tolerance as an example, we have shown that technological advances that improve resilience can further enhance agricultural productivity by causing farmers to re-optimize their production practices. Not accounting for this re-optimization as a result of technological change leads to a large under-estimation of the return from investing in research and development in agriculture. 


\section{Tables}

Table 1: Characteristics of sample villages and other low-lying villages in Odisha, West Bengal, and Bihar

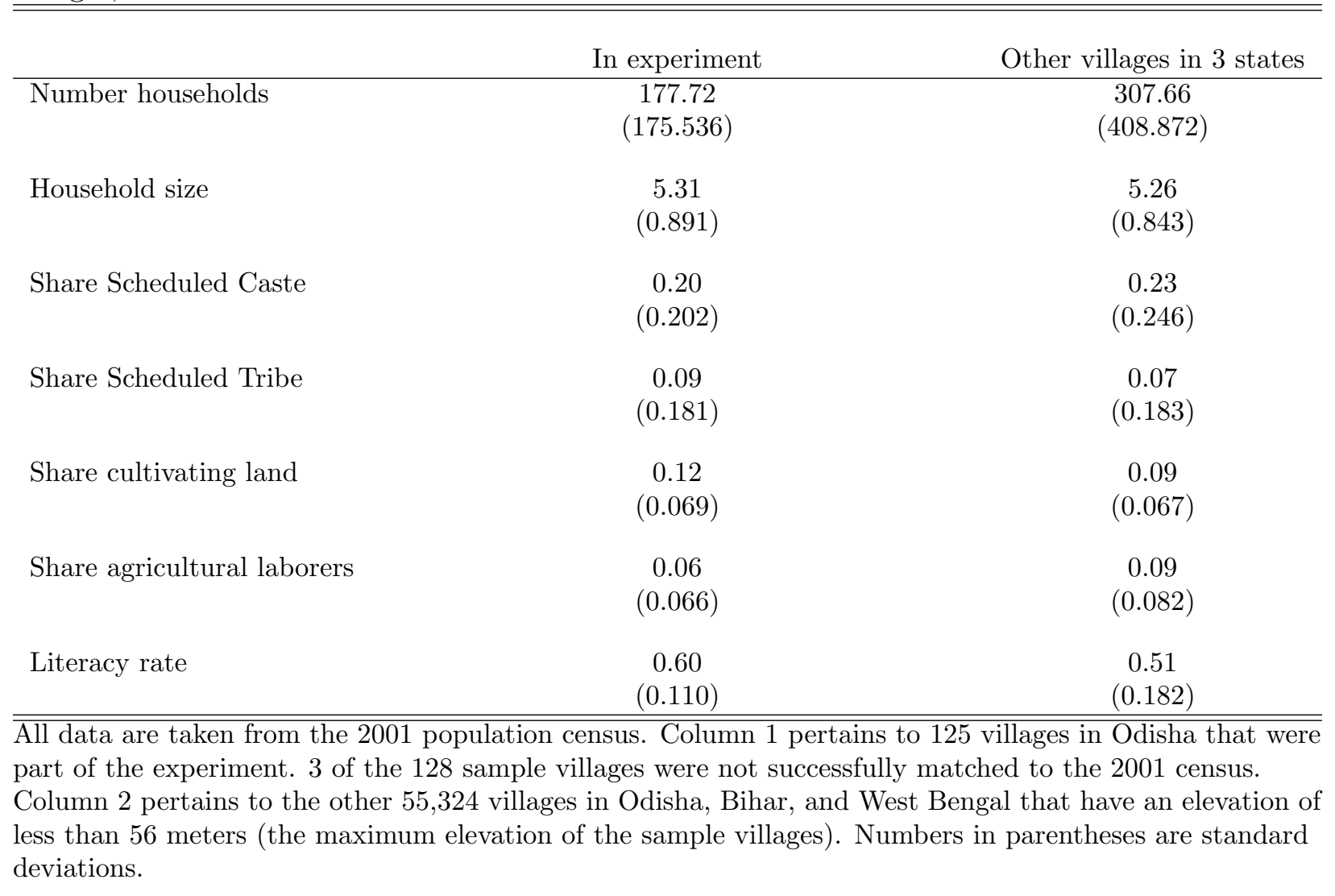


Table 2: Mean values of household characteristics and flood exposure of plots by treatment status

\begin{tabular}{llll}
\hline \hline & & & \\
& Control & Treatment & P-value of difference \\
\hline Panel A: Household characteristics & & & 0.22 \\
Land owned in hectares & 0.810 & 0.868 & 0.82 \\
HH has private tubewell & 0.332 & 0.325 & 0.09 \\
HH has piped water & 0.035 & 0.057 & 0.92 \\
HH has refrigerator & 0.078 & 0.076 & 0.46 \\
HH has television & 0.628 & 0.605 & 0.83 \\
Education of farmer & 6.896 & 6.946 & 0.44 \\
Age of farmer & 51.191 & 51.783 & 0.78 \\
HH has thatched roof & 0.557 & 0.548 & 0.03 \\
HH has latrine & 0.289 & 0.354 & 0.38 \\
HH has electricity & 0.843 & 0.822 & 0.64 \\
HH has below poverty line card & 0.574 & 0.559 & 0.34 \\
ST or SC & 0.189 & 0.176 & 0.34 \\
Panel B: Flood exposure of cultivated plots & & & 0.37 \\
Share plots low land & 0.335 & 0.357 & \\
Share plots medium land & 0.569 & 0.571 & 0.067 \\
Share plots high land & 0.081 & 5.887 & \\
Average flood duration in year 1 & 5.518 & & 0.34 \\
\hline \hline Joint p-value of household characteristics & 0.26 & \\
\hline
\end{tabular}

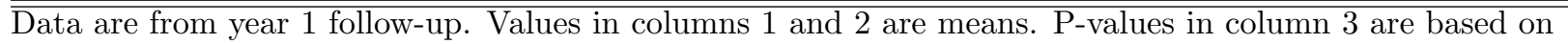
t-tests of equality of means. ST refers to Scheduled Tribe and SC refers to Scheduled Caste. The p-value from the joint regression is the p-value from the joint test of all covariates when treatment assignment is regressed on all covariates. 
Table 3: Effects on cultivation practices

\begin{tabular}{|c|c|c|c|c|c|}
\hline & \multicolumn{5}{|c|}{ Panel A: Year 1} \\
\hline & $\begin{array}{c}(1) \\
\text { Area planted }\end{array}$ & $\begin{array}{c}(2) \\
\log \text { area }\end{array}$ & $\begin{array}{c}(3) \\
\text { Use Swarna }\end{array}$ & $\begin{array}{c}(4) \\
\text { Use TV }\end{array}$ & $\begin{array}{c}(5) \\
\text { Broadcast }\end{array}$ \\
\hline $\begin{array}{l}\text { Original minikit } \\
\text { recipient }\end{array}$ & $\begin{array}{c}0.068 \\
(0.045)\end{array}$ & $\begin{array}{l}0.088^{*} \\
(0.048)\end{array}$ & $\begin{array}{c}-0.157^{* * *} \\
(0.018)\end{array}$ & $\begin{array}{c}-0.029^{*} \\
(0.016)\end{array}$ & $\begin{array}{l}-0.022^{*} \\
(0.012)\end{array}$ \\
\hline Block Fixed Effects & Yes & Yes & Yes & Yes & Yes \\
\hline Mean of Dep Variable & 0.92 & -0.36 & 0.47 & 0.21 & 0.10 \\
\hline Number of Observations & 1248 & 1238 & 4215 & 4214 & 4221 \\
\hline \multirow[t]{4}{*}{$\mathrm{R}$ squared } & 0.167 & 0.197 & 0.129 & 0.153 & 0.094 \\
\hline & \multicolumn{5}{|c|}{ Panel B: Year 2} \\
\hline & (1) & (2) & (3) & (4) & $(5)$ \\
\hline & Area planted & Log area & Use Swarna & Use TV & Broadcast \\
\hline $\begin{array}{l}\text { Original minikit } \\
\text { recipient }\end{array}$ & $\begin{array}{l}0.109^{*} \\
(0.056)\end{array}$ & $\begin{array}{l}0.098^{* *} \\
(0.044)\end{array}$ & $\begin{array}{c}-0.101^{* * *} \\
(0.017)\end{array}$ & $\begin{array}{c}-0.041^{* *} \\
(0.016)\end{array}$ & $\begin{array}{c}-0.063^{* * *} \\
(0.017)\end{array}$ \\
\hline Block Fixed Effects & Yes & Yes & Yes & Yes & Yes \\
\hline Mean of Dep Variable & 1.00 & -0.20 & 0.36 & 0.28 & 0.19 \\
\hline Number of Observations & 1237 & 1175 & 4589 & 4588 & 4582 \\
\hline $\mathrm{R}$ squared & 0.112 & 0.161 & 0.115 & 0.270 & 0.242 \\
\hline \multicolumn{6}{|c|}{$\begin{array}{l}\text { Dependent variable is total rice area planted in hectares (column } 1), \log \text { of total rice area (column } 2) \text {, and } \\
\text { indicator for using Swarna on the plot (column } 3) \text {, an indicator for using a traditional seed variety on the } \\
\text { plot (column } 4) \text { and an indicator for planting the plot using the broadcasting technique (column } 5) \text {. The } \\
\text { observations are at the farmer level in columns } 1 \text { and } 2 \text { and at the plot level in columns } 3 \text { through } 5 \text {. } \\
\text { Standard errors that are clustered at the village level are reported in parentheses. Asterisks indicate } \\
\text { statistical significance at the } 1 \%^{* * *}, 5 \%^{* *} \text {, and } 10 \%^{*} \text { levels. }\end{array}$} \\
\hline
\end{tabular}


Table 4: Effects on fertilizer usage during year two, conditional on cultivated area

\begin{tabular}{|c|c|c|c|c|c|}
\hline & $\begin{array}{l}\text { (1) } \\
\text { All }\end{array}$ & $\begin{array}{c}(2) \\
\text { Urea }\end{array}$ & $\begin{array}{c}(3) \\
\text { DAP }\end{array}$ & $\begin{array}{c}(4) \\
\text { MOP }\end{array}$ & $\begin{array}{c}(5) \\
\text { Gromor }\end{array}$ \\
\hline Original minikit recipient & $\begin{array}{l}396.703^{* *} \\
(179.631)\end{array}$ & $\begin{array}{c}13.428 \\
(34.372)\end{array}$ & $\begin{array}{c}393.768^{* * *} \\
(136.410)\end{array}$ & $\begin{array}{c}90.579 \\
(58.170)\end{array}$ & $\begin{array}{r}-101.073 \\
(67.759)\end{array}$ \\
\hline Rice area (hectares) & $\begin{array}{c}3835.891^{* * *} \\
(315.559)\end{array}$ & $\begin{array}{c}694.814^{* * *} \\
(108.483)\end{array}$ & $\begin{array}{c}2288.634^{* * *} \\
(253.521)\end{array}$ & $\begin{array}{c}623.535^{* * *} \\
(132.287)\end{array}$ & $\begin{array}{c}228.909^{* * *} \\
(66.481)\end{array}$ \\
\hline Block Fixed Effects & Yes & Yes & Yes & Yes & Yes \\
\hline Mean of Dep Variable & 3781.48 & 664.70 & 2016.80 & 702.82 & 397.15 \\
\hline Number of Observations & 1237 & 1237 & 1237 & 1237 & 1237 \\
\hline $\mathrm{R}$ squared & 0.619 & 0.496 & 0.526 & 0.279 & 0.064 \\
\hline
\end{tabular}

Dependent variable is fertilizer expenditure in Rupees. The column labels indicate the type of fertilizer. All observations are from year two of the experiment and are at the farmer level. Standard errors that are clustered at the village level are reported in parentheses. Asterisks indicate statistical significance at the $1 \%^{* * *}, 5 \%^{* *}$, and $10 \% *$ levels. 
Table 5: Effects on rice storage and credit uptake

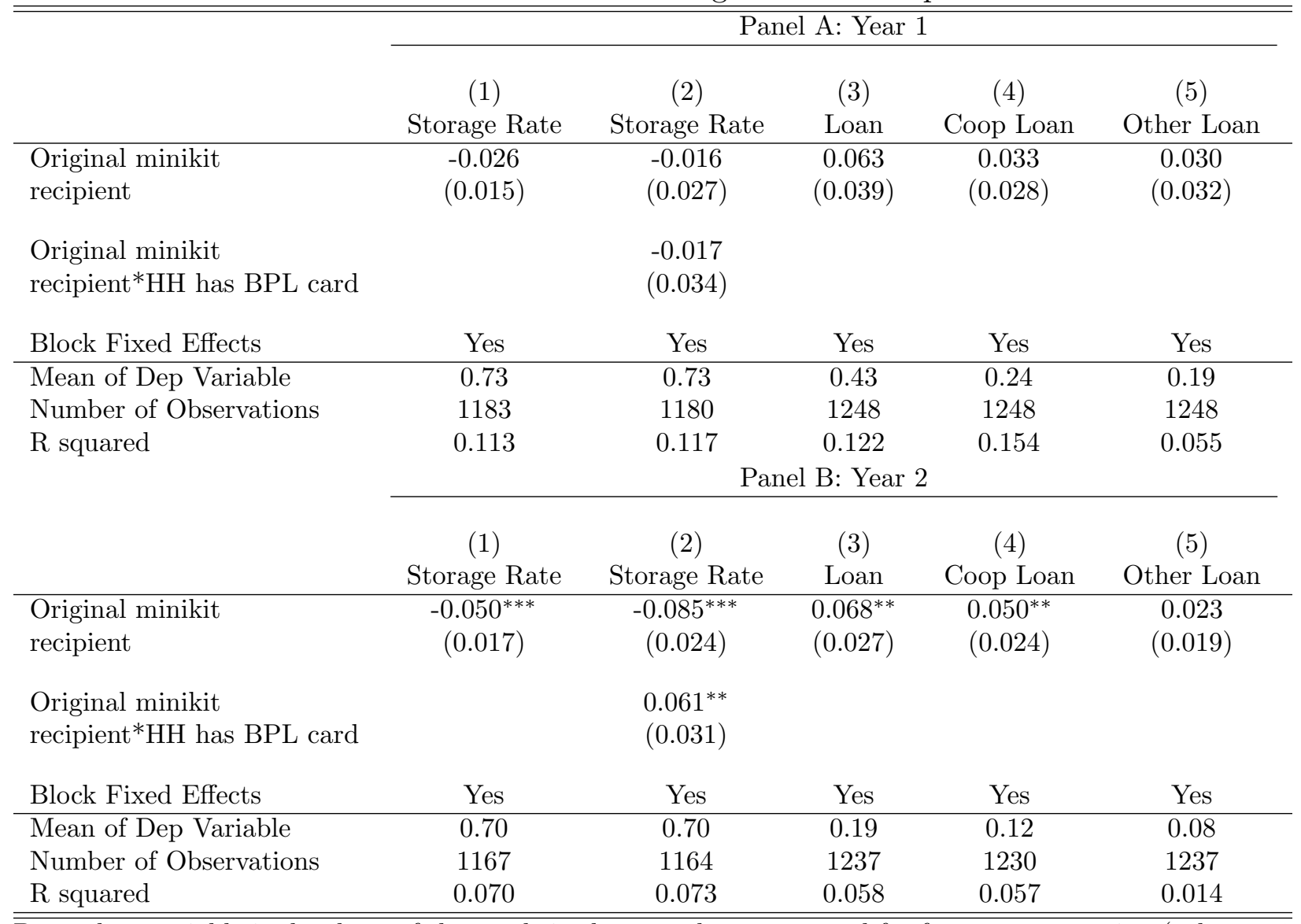

$\overline{\text { Dependent variable is the share of the total rice harvest that was stored for future consumption (columns } 1}$ and 2), an indicator for having a loan (column 3), an indicator for having a loan from an agricultural cooperative (column 4), and an indicator for having a loan from another source (column 5). Other sources are banks, input sellers, Self-Help groups, MFI's, friends/relatives, or money lenders. Standard errors that are clustered at the village level are reported in parentheses. Asterisks indicate statistical significance at the $1 \%^{* * *}, 5 \%^{* *}$, and $10 \%^{*}$ levels. 
Table 6: Effects on productivity

\begin{tabular}{|c|c|c|c|c|c|}
\hline & \multirow{2}{*}{$\begin{array}{c}\text { Year } 1 \\
(1)\end{array}$} & \multicolumn{4}{|c|}{ Year 2} \\
\hline & & (2) & (3) & $(4)$ & (5) \\
\hline Original minikit recipient & $\begin{array}{c}314.97^{* * *} \\
(86.28)\end{array}$ & $\begin{array}{c}283.45^{* * *} \\
(77.48)\end{array}$ & $\begin{array}{c}230.30^{* * *} \\
(73.73)\end{array}$ & $\begin{array}{c}196.54^{* * *} \\
(68.06)\end{array}$ & $\begin{array}{c}169.14^{* *} \\
(64.84)\end{array}$ \\
\hline Broadcast planting & & & $\begin{array}{c}-801.22^{* * *} \\
(129.45)\end{array}$ & $\begin{array}{c}-679.36^{* * *} \\
(117.53)\end{array}$ & $\begin{array}{c}-419.08^{* * *} \\
(108.50)\end{array}$ \\
\hline Tons fertilizer per hectare & & & & $\begin{array}{c}4350.39^{* * *} \\
(997.70)\end{array}$ & $\begin{array}{c}3237.30^{* * *} \\
(831.35)\end{array}$ \\
\hline Tons fertilizer per hectare ${ }^{2}$ & & & & $\begin{array}{c}-4025.26^{* *} \\
(1628.52)\end{array}$ & $\begin{array}{c}-2942.84^{* *} \\
(1266.48)\end{array}$ \\
\hline Traditional variety & & & & & $\begin{array}{c}-442.46^{* * *} \\
(70.86)\end{array}$ \\
\hline Irrigated & & & & & $\begin{array}{c}711.64^{* * *} \\
(92.21)\end{array}$ \\
\hline Has credit & & & & & $\begin{array}{c}150.79^{* *} \\
(69.04)\end{array}$ \\
\hline Block Fixed Effects & Yes & Yes & Yes & Yes & Yes \\
\hline Mean of Dep Variable & 2213.39 & 2817.97 & 2819.53 & 2819.53 & 2819.13 \\
\hline Number of Observations & 4184 & 4573 & 4568 & 4568 & 4514 \\
\hline $\mathrm{R}$ squared & 0.409 & 0.159 & 0.200 & 0.236 & 0.302 \\
\hline
\end{tabular}

Dependent variable in all regressions is yield in $\mathrm{kg} / \mathrm{hectare}$. Estimation data are at the plot level.

Broadcast planting, traditional variety, and irrigated are measured at the plot level; fertilizer per hectare and credit are measured at the farmer level. Standard errors that are clustered at the village level are reported in parentheses. Asterisks indicate statistical significance at the $1 \%^{* * *}, 5 \%^{* *}$, and $10 \%^{*}$ levels. 


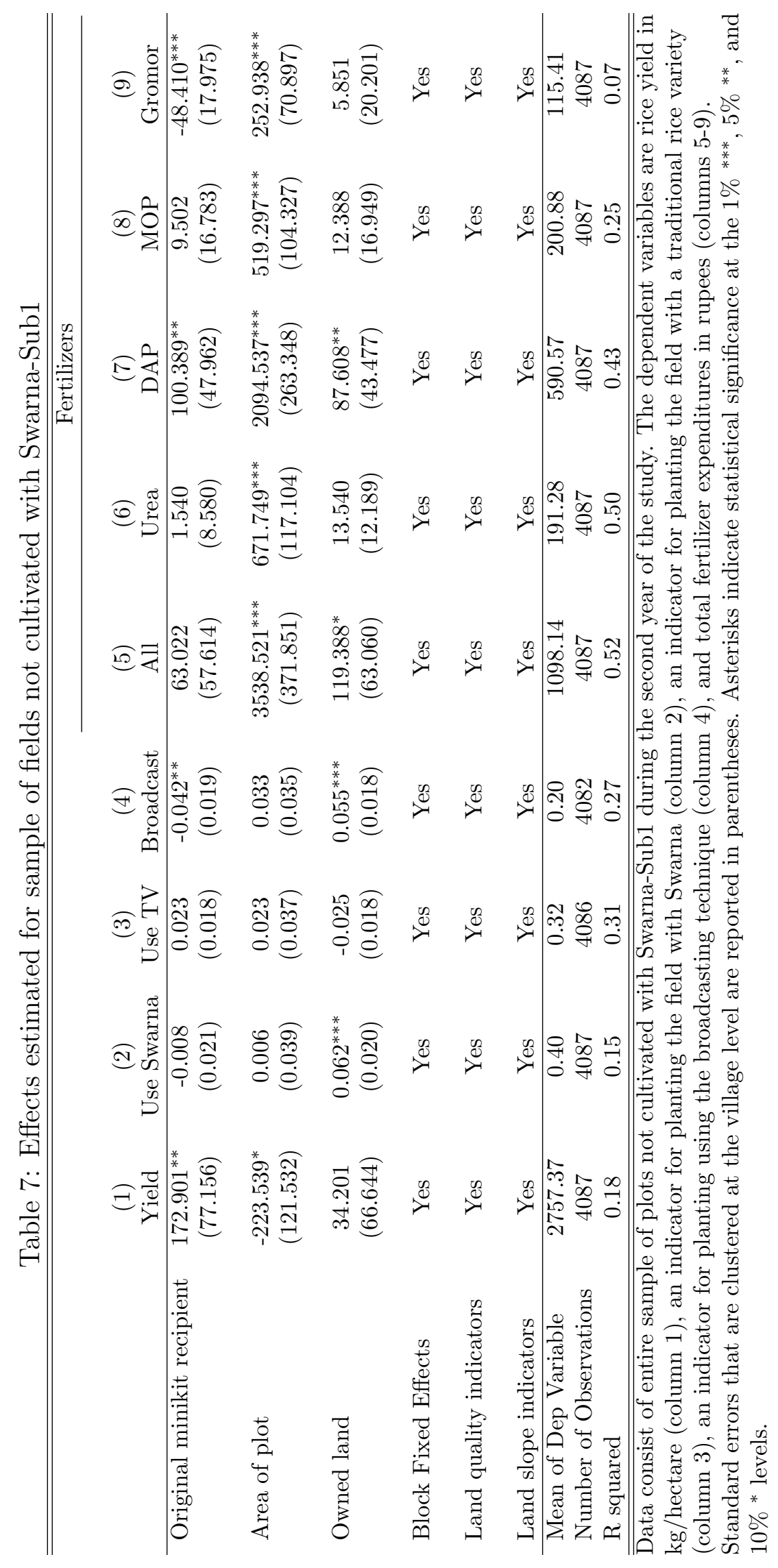




\section{Figures}

Figure 1: Location of villages in Odisha

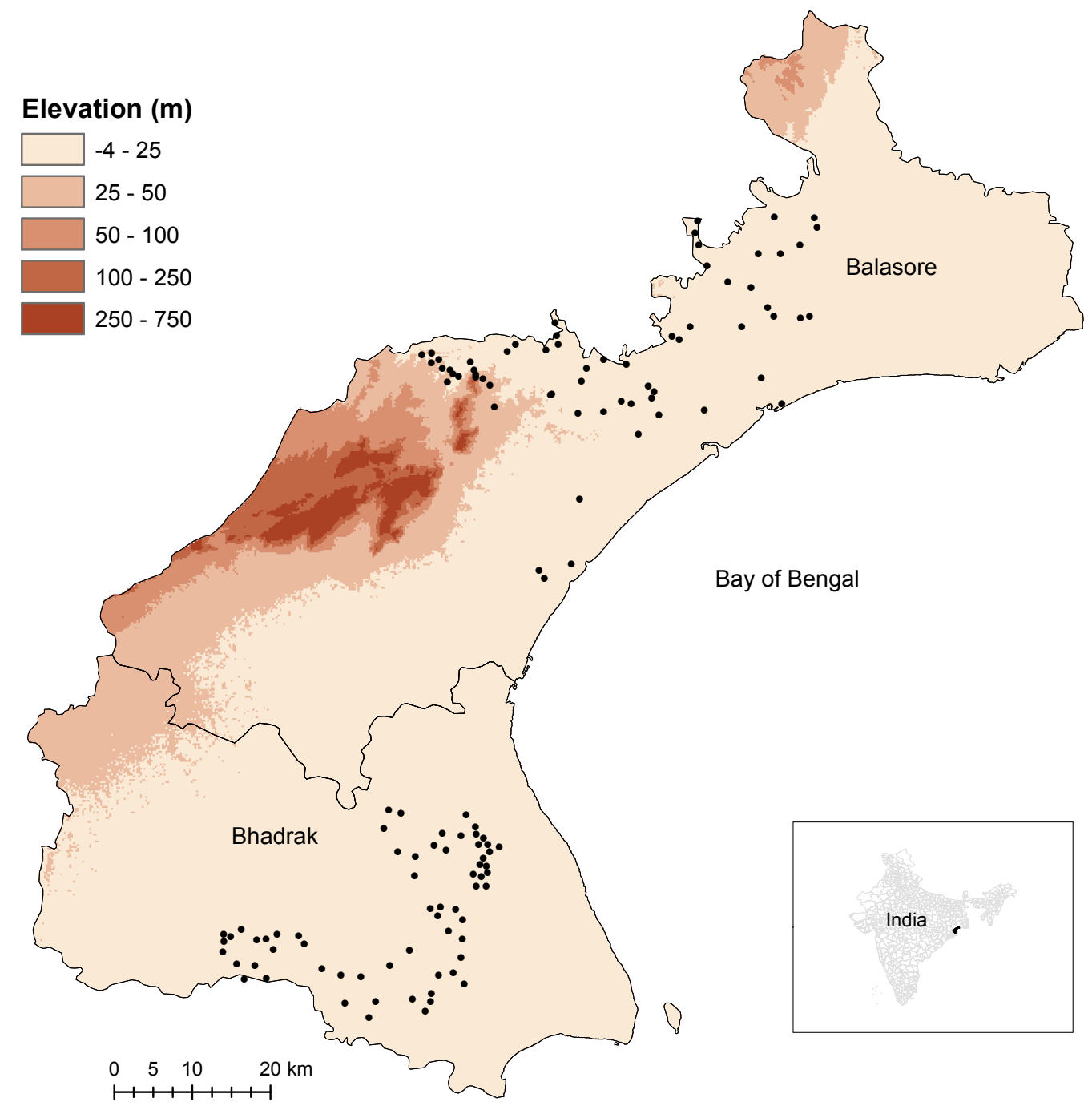


Figure 2: Kernel densities of plot-level yield by treatment status
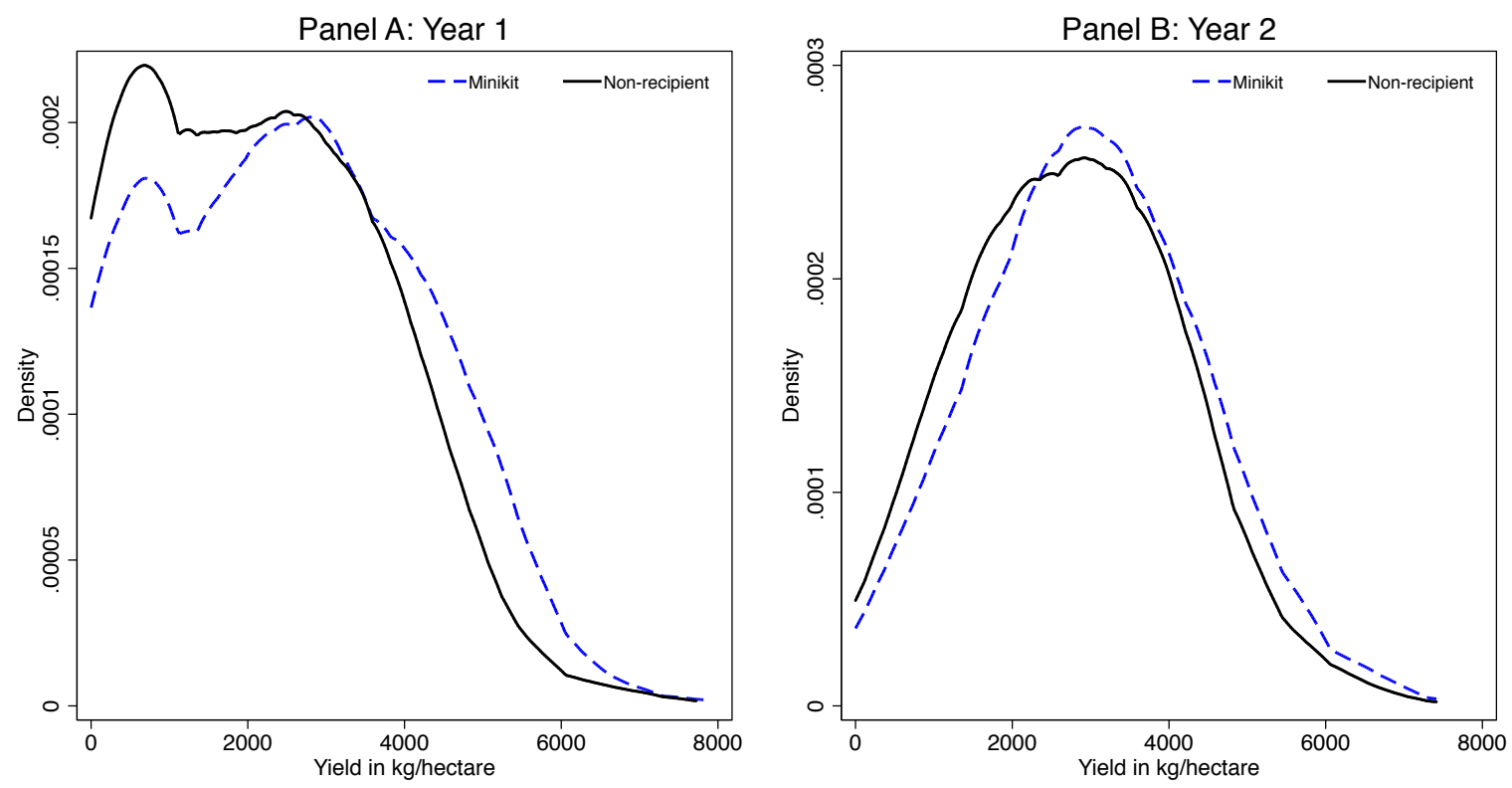

Notes: Figure displays estimated kernel densities of yield (kg per ha) for both years of the study. Densities are estimated across all cultivated plots. The blue dashed lines are densities for all plots cultivated by minikit recipients, regardless of seed variety choice on those plots. The black lines are densities for all plots cultivated by control farmers. 
Figure 3: Distribution of flooding for sample plots: 2002-2008 and 2011-2014

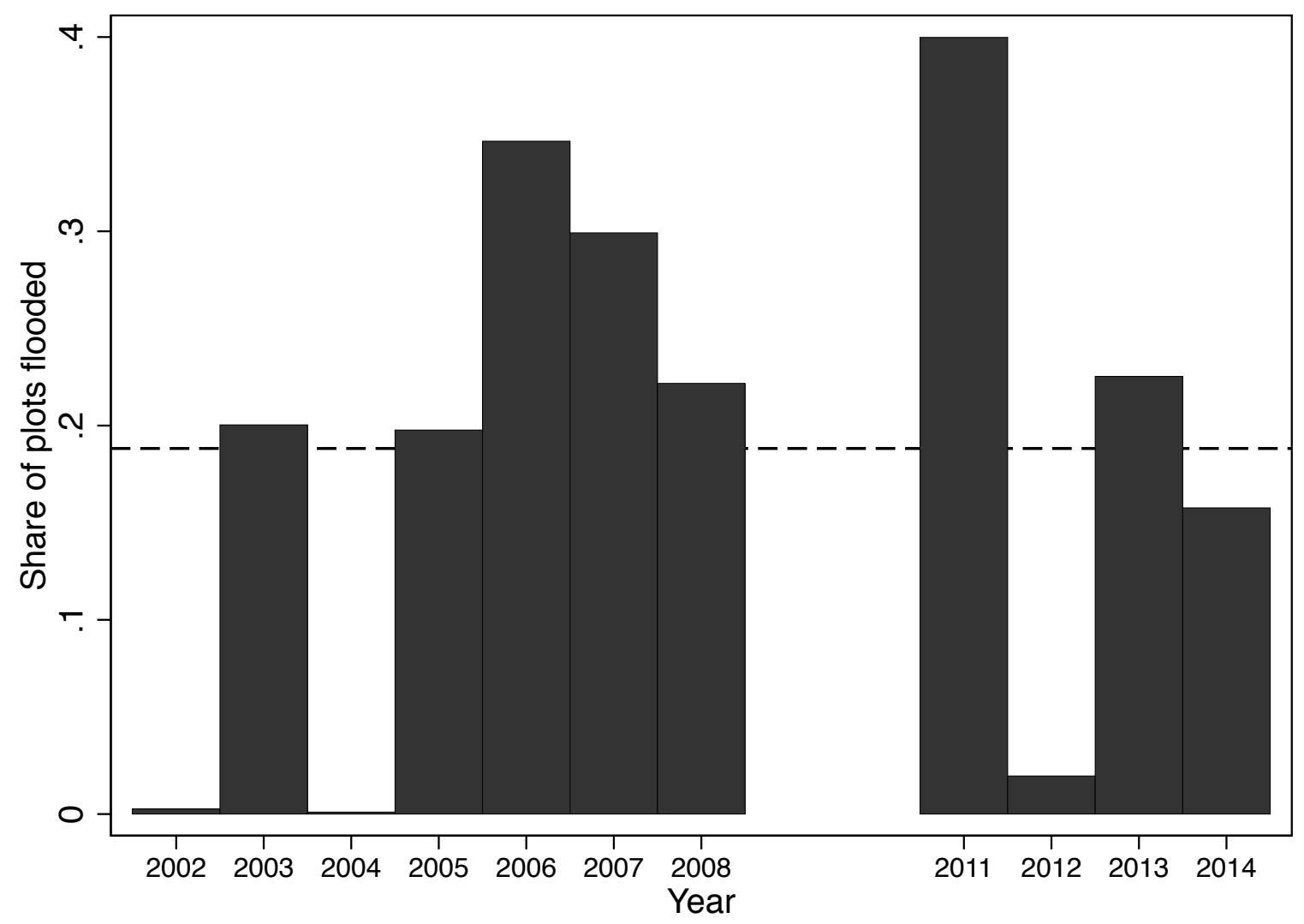

Notes: Figure shows the distribution of flooding across time for 1,123 plots that were cultivated by farmers in our sample during year 1 of the study. The height of each bar is the share of the 1,123 plots that were flooded at least once during the relevant season. Satellite imagery from MODIS for the years 2002-2008 and 2011-2014 were matched with the GIS coordinates of the plot to determine whether a given plot was flooded in each year. The horizontal dashed line represents the overall probability of flooding for plots in the sample, which is 0.19 across the 11 years. 


\section{References}

Anderson, Michael L. 2008. "Multiple inference and gender differences in the effects of early intervention: A reevaluation of the Abecedarian, Perry Preschool, and Early Training Projects." Journal of the American Statistical Association 103 (484):1481-1495.

Ashraf, Nava, Xavier Giné, and Dean Karlan. 2009. "Finding missing markets (and a disturbing epilogue): Evidence from an export crop adoption and marketing intervention in Kenya." American Journal of Agricultural Economics 91 (4):973-990.

Bailey-Serres, J., T. Fukao, P. Ronald, A. Ismail, S. Heuer, and D. Mackill. 2010. "Submergence tolerant rice: SUB1's journey from landrace to modern cultivar." Rice 3 (2):138-147.

Beaman, Lori A, Dean Karlan, Bram Thuysbaert, and Christopher R Udry. 2013. "Profitability of fertilizer: Experimental evidence from female rice farmers in Mali." American Economic Review Papers 83 Proceedings 103 (3):381-386.

Benjamini, Yoav, Abba M Krieger, and Daniel Yekutieli. 2006. "Adaptive linear step-up procedures that control the false discovery rate." Biometrika 93 (3):491-507.

Boucher, Stephen R, Michael R Carter, and Catherine Guirkinger. 2008. "Risk rationing and wealth effects in credit markets: Theory and implications for agricultural development." American Journal of Agricultural Economics 90 (2):409-423.

Cai, Jing, Alain de Janvry, and Elisabeth Sadoulet. 2015. "Social Networks and the Decision to Insure." American Economic Journal: Applied Economics 7 (2):81-108.

Capell, Teresa, Ludovic Bassie, and Paul Christou. 2004. "Modulation of the polyamine biosynthetic pathway in transgenic rice confers tolerance to drought stress." Proceedings of the National Academy of Sciences 101 (26):9909-9914.

Carter, Michael R, Francisco Galarza, and Stephen Boucher. 2007. "Underwriting areabased yield insurance to crowd-in credit supply and demand." Savings and Development $31(3): 335-362$.

Cole, Shawn, Xavier Giné, Jeremy Tobacman, Petia Topalova, Robert Townsend, and James Vickery. 2013. "Barriers to Household Risk Management: Evidence from India." American Economic Journal: Applied Economics 5 (1):104-135.

Cole, Shawn, Xavier Giné, and James Vickery. 2013. "How Does Risk Management Influence Production Decisions? Evidence from a Field Experiment." Unpublished . 
Dar, Manzoor H, Alain de Janvry, Kyle Emerick, David Raitzer, and Elisabeth Sadoulet. 2013. "Flood-tolerant rice reduces yield variability and raises expected yield, differentially benefitting socially disadvantaged groups." Scientific Reports 3.

Dercon, Stefan, Ruth Vargas Hill, Daniel Clarke, Ingo Outes-Leon, and Alemayehu Seyoum Taffesse. 2014. "Offering rainfall insurance to informal insurance groups: evidence from a field experiment in Ethiopia." Journal of Development Economics 106 (2014):132143.

Donovan, Kevin. 2014. "Agricultural Risk, Intermediate Inputs, and Cross-Country Productivity Differences." Unpublished .

Duflo, Esther, Michael Kremer, and Jonathan Robinson. 2011. "Nudging Farmers to Use Fertilizer: Theory and Experimental Evidence from Kenya." American Economic Review 101 (6):2350-2390.

Elabed, Ghada and Michael R Carter. 2014. "Ex-ante impacts of Agricultural Insurance: Evidence from a Field Experiment in Mali." Unpublished .

Evenson, R.E. and D. Gollin. 2003. "Assessing the impact of the Green Revolution, 1960 to 2000." Science 300 (5620):758-762.

Fujino, Kenji, Hiroshi Sekiguchi, Yasuyuki Matsuda, Kazuhiko Sugimoto, Kazuko Ono, and Masahiro Yano. 2008. "Molecular identification of a major quantitative trait locus, qLTG3-1, controlling low-temperature germinability in rice." Proceedings of the National Academy of Sciences 105 (34):12623-12628.

Fukao, Takeshi and Julia Bailey-Serres. 2008. "Submergence tolerance conferred by Sub1A is mediated by SLR1 and SLRL1 restriction of gibberellin responses in rice." Proceedings of the National Academy of Sciences 105 (43):16814-16819.

Fulford, Scott L. 2013. "The effects of financial development in the short and long run: Theory and evidence from India." Journal of Development Economics 104:56-72.

Giné, Xavier, Robert Townsend, and James Vickery. 2008. "Patterns of rainfall insurance participation in rural India." The World Bank Economic Review 22 (3):539-566.

Gollin, Douglas, Stephen Parente, and Richard Rogerson. 2002. "The role of agriculture in development." American Economic Review 92 (2):160-164. 
Hanna, Rema, Sendhil Mullainathan, and Joshua Schwartzstein. 2014. "Learning Through Noticing: Theory and Experimental Evidence From a Field Experiment." Quarterly Journal of Economics 129 (3):1311-1353.

Hattori, Yoko, Keisuke Nagai, Shizuka Furukawa, Xian-Jun Song, Ritsuko Kawano, Hitoshi Sakakibara, Jianzhong Wu, Takashi Matsumoto, Atsushi Yoshimura, Hidemi Kitano et al. 2009. "The ethylene response factors SNORKEL1 and SNORKEL2 allow rice to adapt to deep water." Nature 460 (7258):1026-1030.

Hirabayashi, Yukiko, Roobavannan Mahendran, Sujan Koirala, Lisako Konoshima, Dai Yamazaki, Satoshi Watanabe, Hyungjun Kim, and Shinjiro Kanae. 2013. "Global flood risk under climate change." Nature Climate Change 3:816-821.

Ismail, Abdelbagi M, Uma S Singh, Sudhanshu Singh, Manzoor H Dar, and David J Mackill. 2013. "The contribution of submergence-tolerant (Sub1) rice varieties to food security in flood-prone rainfed lowland areas in Asia." Field Crops Research 152:83-93.

Karaba, Aarati, Shital Dixit, Raffaella Greco, Asaph Aharoni, Kurniawan R Trijatmiko, Nayelli Marsch-Martinez, Arjun Krishnan, Karaba N Nataraja, Makarla Udayakumar, and Andy Pereira. 2007. "Improvement of water use efficiency in rice by expression of HARDY, an Arabidopsis drought and salt tolerance gene." Proceedings of the National Academy of Sciences 104 (39):15270-15275.

Karlan, Dean, Robert Darko Osei, Isaac Osei-Akoto, and Christopher Udry. 2014. "Agricultural decisions after relaxing credit and risk constraints." Quarterly Journal of Economics 129 (2):597-652.

Khush, Gurdev S. 1997. "Origin, dispersal, cultivation and variation of rice." In Oryza: From Molecule to Plant. Springer, 25-34.

Maccini, Sharon and Dean Yang. 2009. "Under the weather: Health, schooling, and economic consequences of early-life rainfall." The American Economic Review 99 (3):1006-1026.

Mackill, DJ, AM Ismail, US Singh, RV Labios, and TR Paris. 2012. "Development and Rapid Adoption of Submergence-Tolerant (SUB1) Rice Varieties." Advances in Agronomy 115:299.

Milligan, Kevin, Enrico Moretti, and Philip Oreopoulos. 2004. "Does education improve citizenship? Evidence from the United States and the United Kingdom." Journal of Public Economics 88 (9):1667-1695. 
Milly, PCD, RT Wetherald, KA Dunne, and TL Delworth. 2002. "Increasing risk of great floods in a changing climate." Nature 415 (6871):514-517.

Mobarak, A Mushfiq and Mark Rosenzweig. 2012. "Selling formal insurance to the informally insured." Unpublished .

Neeraja, CN, R Maghirang-Rodriguez, A Pamplona, S Heuer, BCY Collard, EM Septiningsih, G Vergara, D Sanchez, K Xu, AM Ismail et al. 2007. "A marker-assisted backcross approach for developing submergence-tolerant rice cultivars." Theoretical and Applied Genetics 115 (6):767-776.

Nelson, Donald E, Peter P Repetti, Tom R Adams, Robert A Creelman, Jingrui Wu, David C Warner, Don C Anstrom, Robert J Bensen, Paolo P Castiglioni, Meghan G Donnarummo et al. 2007. "Plant nuclear factor Y (NF-Y) B subunits confer drought tolerance and lead to improved corn yields on water-limited acres." Proceedings of the National Academy of Sciences 104 (42):16450-16455.

Pingali, Prabhu L. 2012. "Green Revolution: Impacts, limits, and the path ahead." Proceedings of the National Academy of Sciences 109 (31):12302-12308.

Rao, AN, DE Johnson, B Sivaprasad, JK Ladha, and AM Mortimer. 2007. "Weed management in direct-seeded rice." Advances in Agronomy 93:153-255.

Singh, S., D.J. Mackill, and A.M. Ismail. 2009. "Responses of SUB1 rice introgression lines to submergence in the field: yield and grain quality." Field Crops Research 113 (1):12-23.

Singh, Sudhanshu, David J Mackill, and Abdelbagi M Ismail. 2011. "Tolerance of longerterm partial stagnant flooding is independent of the SUB1 locus in rice." Field Crops Research 121 (3):311-323.

Suri, Tavneet. 2011. "Selection and comparative advantage in technology adoption." Econometrica 79 (1):159-209.

Townsend, Robert M. 1994. "Risk and insurance in village India." Econometrica 62 (3):539591.

Voesenek, Laurentius ACJ and Julia Bailey-Serres. 2009. "Plant biology: Genetics of highrise rice." Nature 460 (7258):959-960.

World Bank. 2008. World Development Report: Agriculture for Development. Washington, DC: Oxford University Press for the World Bank. 
Xu, K., X. Xu, T. Fukao, P. Canlas, R. Maghirang-Rodriguez, S. Heuer, A.M. Ismail, J. Bailey-Serres, P.C. Ronald, and D.J. Mackill. 2006. "Sub1A is an ethylene-responsefactor-like gene that confers submergence tolerance to rice." Nature 442 (7103):705-708. 


\section{Appendix - For Online Publication}

Table A1: Knowledge and adoption of Swarna-Sub1 by control farmers

\begin{tabular}{lccccc}
\hline \hline & \multicolumn{2}{c}{ Knowledge } & & \multicolumn{2}{c}{ Adoption } \\
\cline { 2 - 3 } \cline { 5 - 6 } & $(1)$ & $(2)$ & & $(3)$ & $(4)$ \\
\hline Treatment village & $0.293^{* * *}$ & $0.299^{* * *}$ & & $0.100^{* * *}$ & $0.094^{* * *}$ \\
& $(0.044)$ & $(0.045)$ & & $(0.023)$ & $(0.023)$ \\
Block Fixed Effects & Yes & Yes & & Yes & Yes \\
Household controls & No & & & No & Yes \\
\hline Mean of Dep Variable & 0.62 & 0.62 & & 0.10 & 0.10 \\
Number of Observations & 928 & 921 & & 928 & 921 \\
R squared & 0.118 & 0.126 & & 0.104 & 0.116 \\
\hline \hline All observalion
\end{tabular}

All observations are from year 2 follow-up survey. Dependent variable in columns 1 and 2 is an indicator variable for ever hearing of Swarna-Sub1 at the time of the second year follow-up. Dependent variable in columns 3 and 4 is an indicator variable for adoption of Swarna-Sub1 during year 2. Standard errors that are clustered at the village level are reported in parentheses. Asterisks indicate statistical significance at the $1 \%^{* * *}, 5 \%^{* *}$, and $10 \%^{*}$ levels. 
Figure A1: Stated reasons for choosing rice varieties during year 2

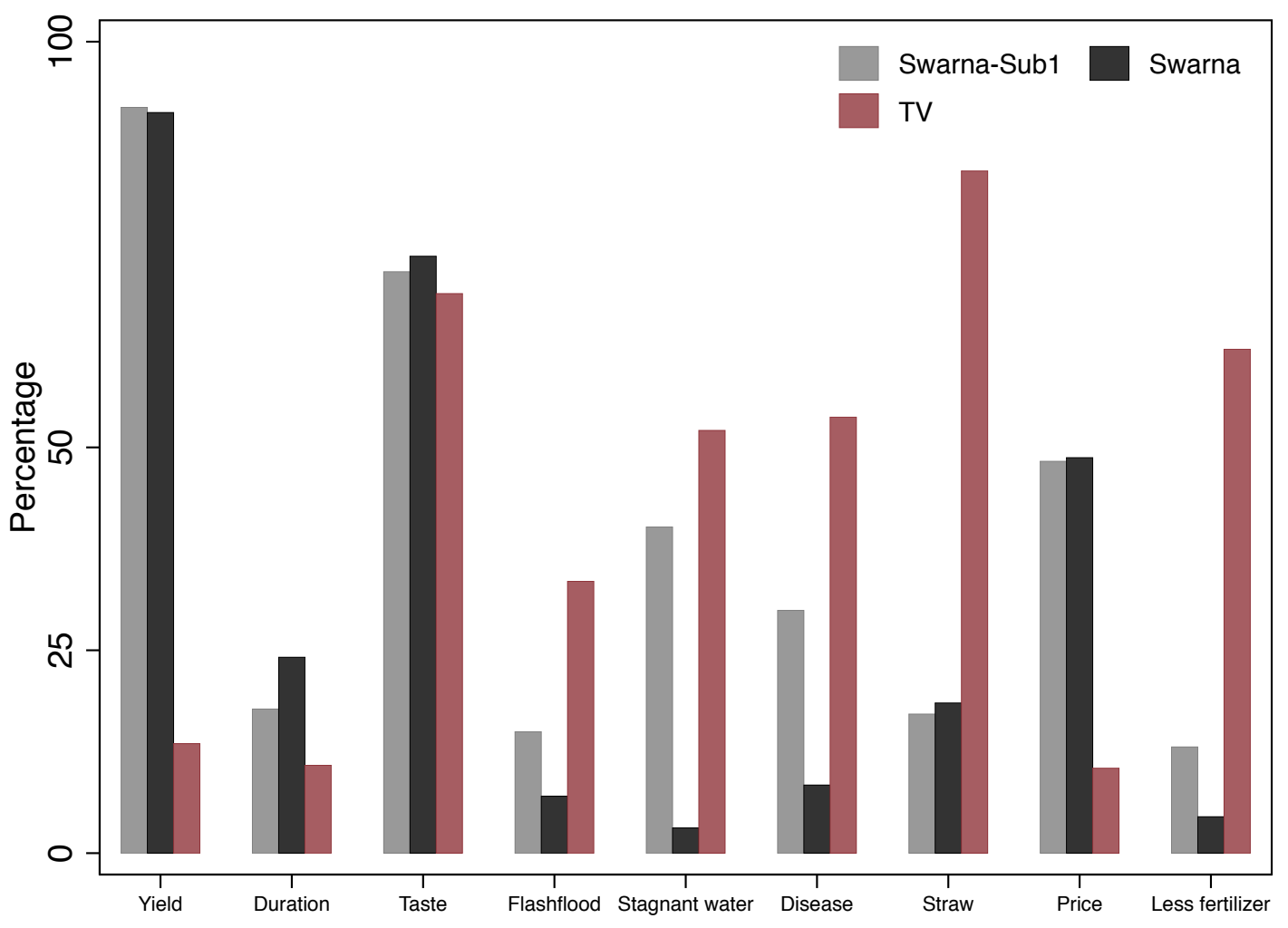

Figure displays percentage of farmers (Swarna and Swarna-Sub1) and percentage of farmer-variety pairs (TV) for which the characteristic on the horizontal axis is a reason the variety was chosen during year 2. For example, over $90 \%$ of farmers cultivating Swarna stated that high yield was one of the reasons for this choice (first grey bar above yield). 
Figure A2: Nonparametric regressions of yield and crop survival on duration of flooding during year one
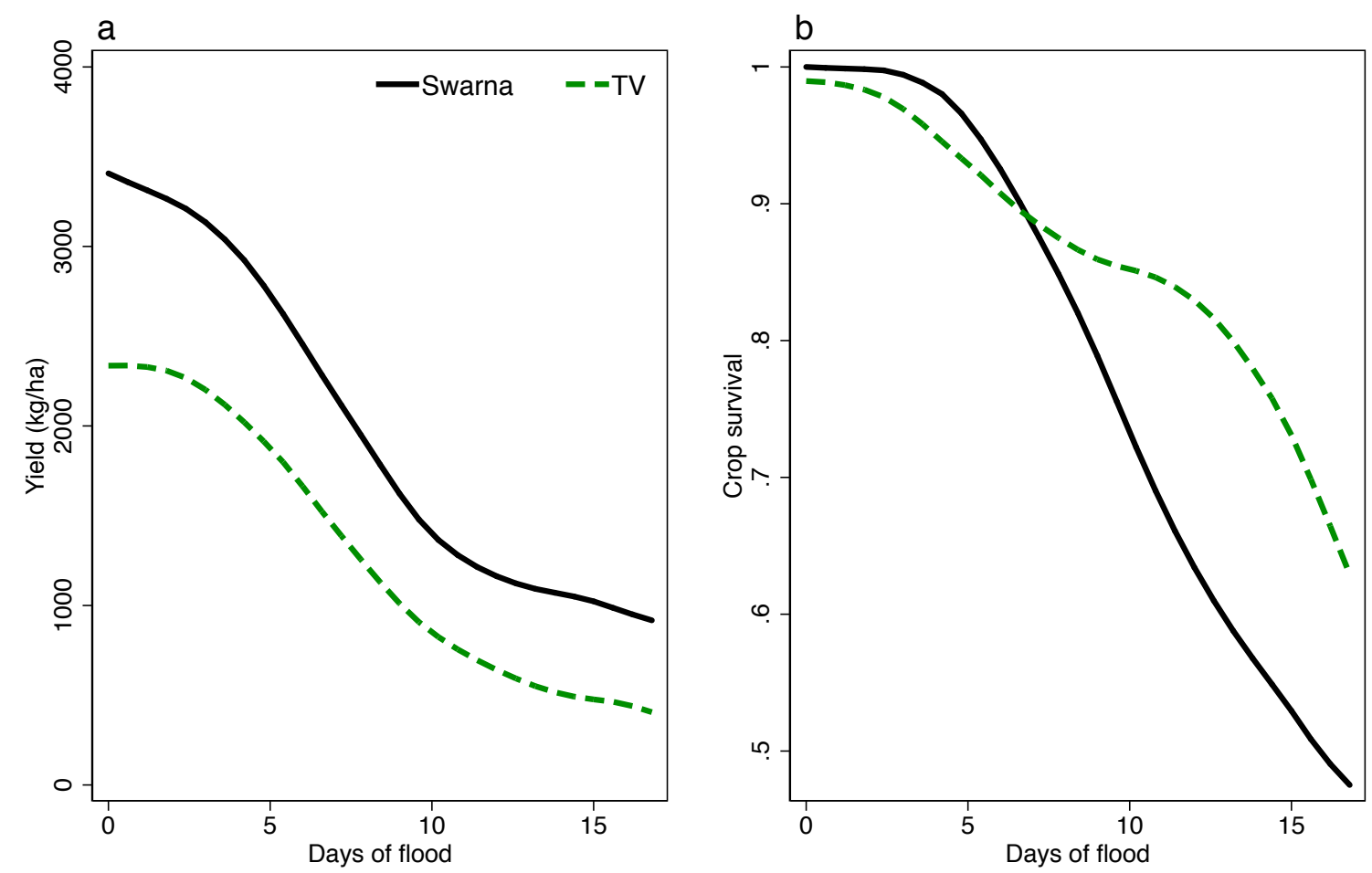

Notes: Figure displays fan regressions of yield and crop survival $(0 / 1)$ on duration of submergence. Estimates are for year one when flooding occurred in part of the sample area. 
Figure A3: Timing of fertilizer applications during first year of study

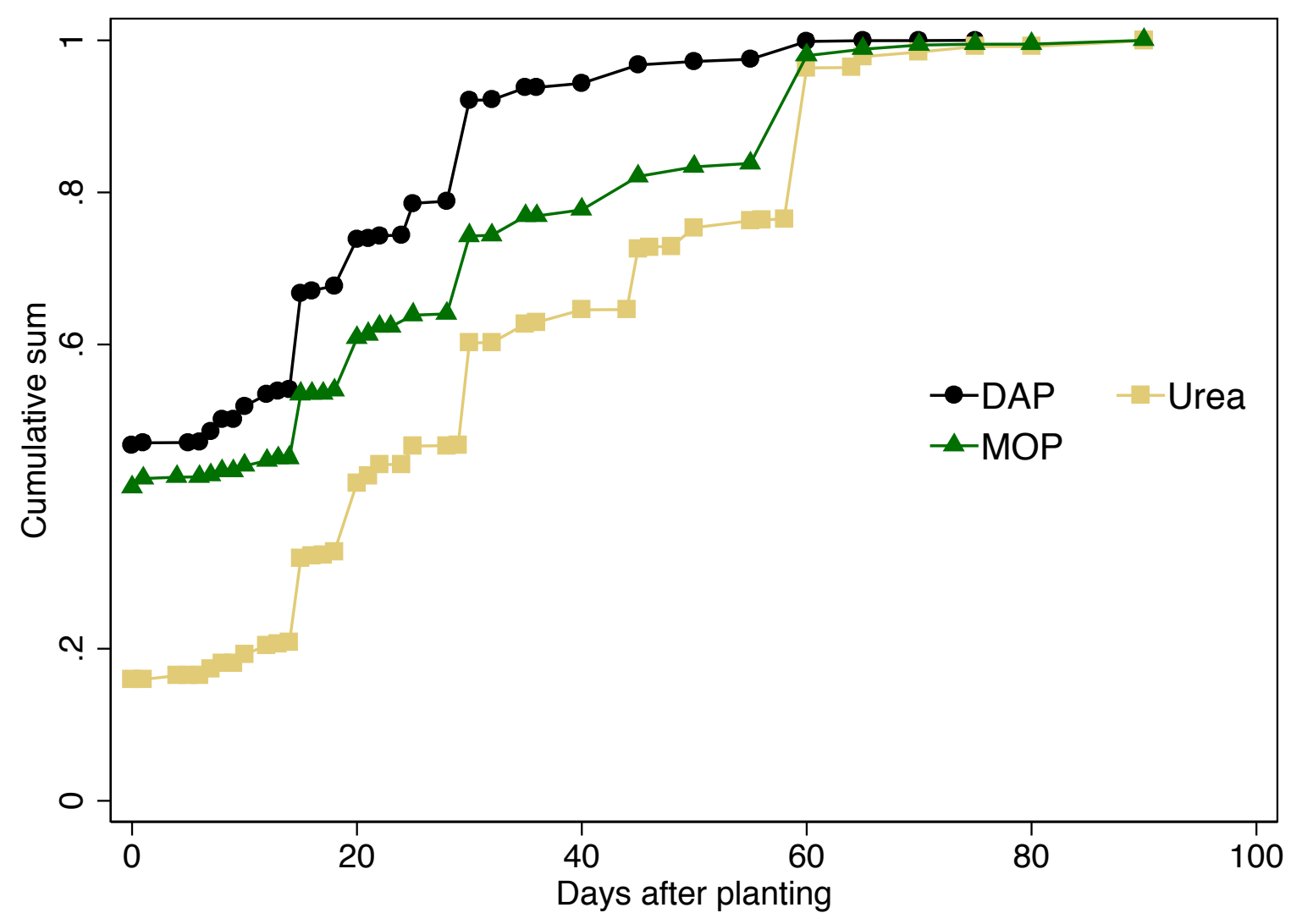

Notes: Figure displays cumulative share of each fertilizer applied by each day in the growing season, where timing is measured in days after planting. Data are for farmers surveyed during the follow-up after year one. Urea is source of nitrogen $(\mathrm{N})$, DAP is primary source of phosphorous $(\mathrm{P})$ and MOP is the source of potassium $(\mathrm{K})$. 
Table A2: Effects on cultivation practices with household controls

\begin{tabular}{|c|c|c|c|c|c|}
\hline & \multicolumn{5}{|c|}{ Panel A: Year 1} \\
\hline & $\begin{array}{c}(1) \\
\text { Area planted }\end{array}$ & $\begin{array}{c}(2) \\
\text { Log area }\end{array}$ & $\begin{array}{c}(3) \\
\text { Use Swarna }\end{array}$ & $\begin{array}{c}(4) \\
\text { Use TV }\end{array}$ & $\begin{array}{c}(5) \\
\text { Broadcast }\end{array}$ \\
\hline $\begin{array}{l}\text { Original minikit } \\
\text { recipient }\end{array}$ & $\begin{array}{c}0.025 \\
(0.031)\end{array}$ & $\begin{array}{c}0.049 \\
(0.037)\end{array}$ & $\begin{array}{c}-0.155^{* * *} \\
(0.018)\end{array}$ & $\begin{array}{c}-0.030^{*} \\
(0.015)\end{array}$ & $\begin{array}{c}-0.027^{* *} \\
(0.013)\end{array}$ \\
\hline Block Fixed Effects & Yes & Yes & Yes & Yes & Yes \\
\hline Household controls & Yes & Yes & Yes & Yes & Yes \\
\hline Mean of Dep Variable & 0.92 & -0.36 & 0.47 & 0.21 & 0.11 \\
\hline Number of Observations & 1238 & 1228 & 4182 & 4181 & 4188 \\
\hline \multirow[t]{4}{*}{$\mathrm{R}$ squared } & 0.652 & 0.602 & 0.137 & 0.168 & 0.122 \\
\hline & \multicolumn{5}{|c|}{ Panel B: Year 2} \\
\hline & (1) & $(2)$ & (3) & (4) & (5) \\
\hline & Area planted & Log area & Use Swarna & Use TV & Broadcast \\
\hline $\begin{array}{l}\text { Original minikit } \\
\text { recipient }\end{array}$ & $\begin{array}{l}0.079^{*} \\
(0.045)\end{array}$ & $\begin{array}{l}0.076^{* *} \\
(0.035)\end{array}$ & $\begin{array}{c}-0.103^{* * *} \\
(0.018)\end{array}$ & $\begin{array}{c}-0.040^{* *} \\
(0.016)\end{array}$ & $\begin{array}{c}-0.062^{* * *} \\
(0.017)\end{array}$ \\
\hline Block Fixed Effects & Yes & Yes & Yes & Yes & Yes \\
\hline Household controls & Yes & Yes & Yes & Yes & Yes \\
\hline Mean of Dep Variable & 1.00 & -0.20 & 0.36 & 0.28 & 0.19 \\
\hline Number of Observations & 1227 & 1165 & 4477 & 4476 & 4470 \\
\hline $\mathrm{R}$ squared & 0.387 & 0.409 & 0.121 & 0.280 & 0.253 \\
\hline
\end{tabular}

Dependent variable is total rice area planted in hectares (column 1), log of total rice area (column 2), an indicator for using Swarna on the plot (column 3), an indicator for using a traditional seed variety on the plot (column 4) and an indicator for planting the plot using the broadcasting technique (column 5). The observations are at the farmer level in columns 1 and 2 and at the plot level in columns 3 and 4. Household controls are all covariates in Panel A of Table 2 of the main text. Standard errors that are clustered at the village level are reported in parentheses. Asterisks indicate statistical significance at the $1 \%{ }^{* *}, 5 \%^{* *}$, and $10 \% *$ levels. 
Table A3: Effects on fertilizer usage during year two with household controls

\begin{tabular}{lccccc}
\hline \hline & $(1)$ & $(2)$ & $(3)$ & $(4)$ & $(5)$ \\
& All & Urea & DAP & MOP & Gromor \\
\hline Original minikit recipient & $397.425^{* *}$ & 12.748 & $395.939^{* * *}$ & $94.914^{*}$ & -106.178 \\
& $(170.766)$ & $(32.999)$ & $(133.021)$ & $(56.425)$ & $(70.838)$ \\
Rice area (hectares) & $3986.428^{* * *}$ & $777.545^{* * *}$ & $2344.337^{* * *}$ & $633.036^{* * *}$ & $231.510^{* * *}$ \\
& $(382.500)$ & $(136.847)$ & $(307.059)$ & $(176.412)$ & $(87.886)$ \\
Block Fixed Effects & & & & & Yes \\
& Yes & Yes & Yes & & Yes \\
Household controls & Yes & Yes & Yes & Yes & Yes \\
\hline Mean of Dep Variable & 3786.37 & 665.80 & 2020.46 & 702.86 & 397.25 \\
Number of Observations & 1227 & 1227 & 1227 & 1227 & 1227 \\
R squared & 0.629 & 0.522 & 0.532 & 0.295 & 0.072 \\
\hline \hline
\end{tabular}

Dependent variable is fertilizer expenditure in Rupees. The column labels indicate the type of fertilizer. All observations are from year two of the experiment and are at the farmer level. Household controls are all covariates in Panel A of Table 2 of the main text. Standard errors that are clustered at the village level are reported in parentheses. Asterisks indicate statistical significance at the $1 \%^{* * *}, 5 \%^{* *}$, and $10 \%^{*}$ levels. 
Table A4: Effects on rice storage and credit uptake with household controls

\begin{tabular}{|c|c|c|c|c|c|}
\hline & \multicolumn{5}{|c|}{ Panel A: Year 1} \\
\hline & $\begin{array}{c}(1) \\
\text { Storage Rate }\end{array}$ & $\begin{array}{c}(2) \\
\text { Storage Rate }\end{array}$ & $\begin{array}{c}(3) \\
\text { Credit }\end{array}$ & $\begin{array}{c}(4) \\
\text { Coop Loan }\end{array}$ & $\begin{array}{c}(5) \\
\text { Other Loan }\end{array}$ \\
\hline $\begin{array}{l}\text { Original minikit } \\
\text { recipient }\end{array}$ & $\begin{array}{l}-0.026^{*} \\
(0.014)\end{array}$ & $\begin{array}{l}-0.012 \\
(0.024)\end{array}$ & $\begin{array}{c}0.059 \\
(0.039)\end{array}$ & $\begin{array}{c}0.033 \\
(0.029)\end{array}$ & $\begin{array}{c}0.026 \\
(0.032)\end{array}$ \\
\hline $\begin{array}{l}\text { Original minikit } \\
\text { recipient*HH has BPL card }\end{array}$ & & $\begin{array}{l}-0.024 \\
(0.032)\end{array}$ & & & \\
\hline Block Fixed Effects & Yes & Yes & Yes & Yes & Yes \\
\hline Household controls & Yes & Yes & Yes & Yes & Yes \\
\hline Mean of Dep Variable & 0.73 & 0.73 & 0.43 & 0.24 & 0.19 \\
\hline Number of Observations & 1175 & 1175 & 1238 & 1238 & 1238 \\
\hline \multirow[t]{3}{*}{$\mathrm{R}$ squared } & 0.172 & 0.172 & 0.147 & 0.163 & 0.078 \\
\hline & \multicolumn{5}{|c|}{ Panel B: Year 2} \\
\hline & $\begin{array}{c}(1) \\
\text { Storage Rate }\end{array}$ & $\begin{array}{c}(2) \\
\text { Storage Rate }\end{array}$ & $\begin{array}{c}(3) \\
\text { Credit }\end{array}$ & $\begin{array}{c}(4) \\
\text { Coop Loan }\end{array}$ & $\begin{array}{c}(5) \\
\text { Other Loan }\end{array}$ \\
\hline $\begin{array}{l}\text { Original minikit } \\
\text { recipient }\end{array}$ & $\begin{array}{c}-0.047^{* * *} \\
(0.018)\end{array}$ & $\begin{array}{c}-0.081^{* * *} \\
(0.024)\end{array}$ & $\begin{array}{l}0.064^{* *} \\
(0.027)\end{array}$ & $\begin{array}{l}0.049^{* *} \\
(0.024)\end{array}$ & $\begin{array}{c}0.018 \\
(0.020)\end{array}$ \\
\hline $\begin{array}{l}\text { Original minikit } \\
\text { recipient*HH has BPL card }\end{array}$ & & $\begin{array}{l}0.061^{* *} \\
(0.030)\end{array}$ & & & \\
\hline Block Fixed Effects & Yes & Yes & Yes & Yes & Yes \\
\hline Household Controls & Yes & Yes & Yes & Yes & Yes \\
\hline Mean of Dep Variable & 0.69 & 0.69 & 0.19 & 0.12 & 0.08 \\
\hline Number of Observations & 1157 & 1157 & 1227 & 1220 & 1227 \\
\hline $\mathrm{R}$ squared & 0.094 & 0.097 & 0.077 & 0.076 & 0.031 \\
\hline
\end{tabular}

$\overline{\text { Dependent variable is the share of the total rice harvest that was stored for future consumption (columns } 1}$ and 2), an indicator for having a loan (column 3), an indicator for having a loan from an agricultural cooperative (column 4), and an indicator for having a loan from another source (column 5). Other sources are banks, input sellers, Self-Help groups (SHG's), MFI's, friends/relatives, or money lenders. Household controls are all covariates in Panel A of Table 2 of the main text. Standard errors that are clustered at the village level are reported in parentheses. Asterisks indicate statistical significance at the $1 \%^{* * *}, 5 \%^{* *}$, and $10 \%$ * levels. 
Table A5: Effects on productivity with household controls

\begin{tabular}{|c|c|c|c|c|c|}
\hline & \multirow{2}{*}{$\begin{array}{c}\text { Year } 1 \\
(1)\end{array}$} & \multicolumn{4}{|c|}{ Year 2} \\
\hline & & $(2)$ & (3) & $(4)$ & (5) \\
\hline Original minikit recipient & $\begin{array}{c}316.75^{* * *} \\
(89.62)\end{array}$ & $\begin{array}{c}299.92^{* * *} \\
(76.68)\end{array}$ & $\begin{array}{c}248.70^{* * *} \\
(73.51)\end{array}$ & $\begin{array}{c}215.41^{* * *} \\
(68.24)\end{array}$ & $\begin{array}{c}187.07^{* * *} \\
(65.69)\end{array}$ \\
\hline Broadcast planting & & & $\begin{array}{c}-786.57^{* * *} \\
(127.03)\end{array}$ & $\begin{array}{c}-657.66^{* * *} \\
(115.31)\end{array}$ & $\begin{array}{c}-388.22^{* * *} \\
(104.70)\end{array}$ \\
\hline Tons fertilizer per hectare & & & & $\begin{array}{c}4386.63^{* * *} \\
(980.85)\end{array}$ & $\begin{array}{c}3339.31^{* * *} \\
(815.51)\end{array}$ \\
\hline Tons fertilizer per hectare ${ }^{2}$ & & & & $\begin{array}{c}-3924.83^{* *} \\
(1592.65)\end{array}$ & $\begin{array}{c}-2939.92^{* *} \\
(1251.44)\end{array}$ \\
\hline Traditional variety & & & & & $\begin{array}{c}-460.26^{* * *} \\
(70.36)\end{array}$ \\
\hline Irrigated & & & & & $\begin{array}{c}712.93^{* * *} \\
(93.73)\end{array}$ \\
\hline Has credit & & & & & $\begin{array}{c}136.09^{* *} \\
(68.06)\end{array}$ \\
\hline Block Fixed Effects & Yes & Yes & Yes & Yes & Yes \\
\hline Household Controls & Yes & Yes & Yes & Yes & Yes \\
\hline Mean of Dep Variable & 2220.76 & 2809.62 & 2811.20 & 2811.20 & 2810.69 \\
\hline Number of Observations & 4151 & 4461 & 4456 & 4456 & 4402 \\
\hline $\mathrm{R}$ squared & 0.421 & 0.179 & 0.218 & 0.254 & 0.320 \\
\hline
\end{tabular}

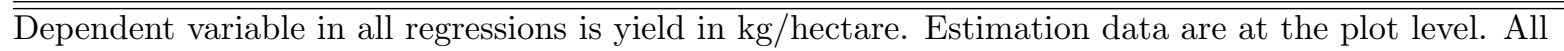
independent variables are measured at the plot level, except for fertilizer per hectare, which is measured at the farmer level. Household controls are all covariates in Panel A of Table 2 of the main text. Standard errors that are clustered at the village level are reported in parentheses. Asterisks indicate statistical significance at the $1 \%^{* * *}, 5 \%^{* *}$, and $10 \%^{*}$ levels. 


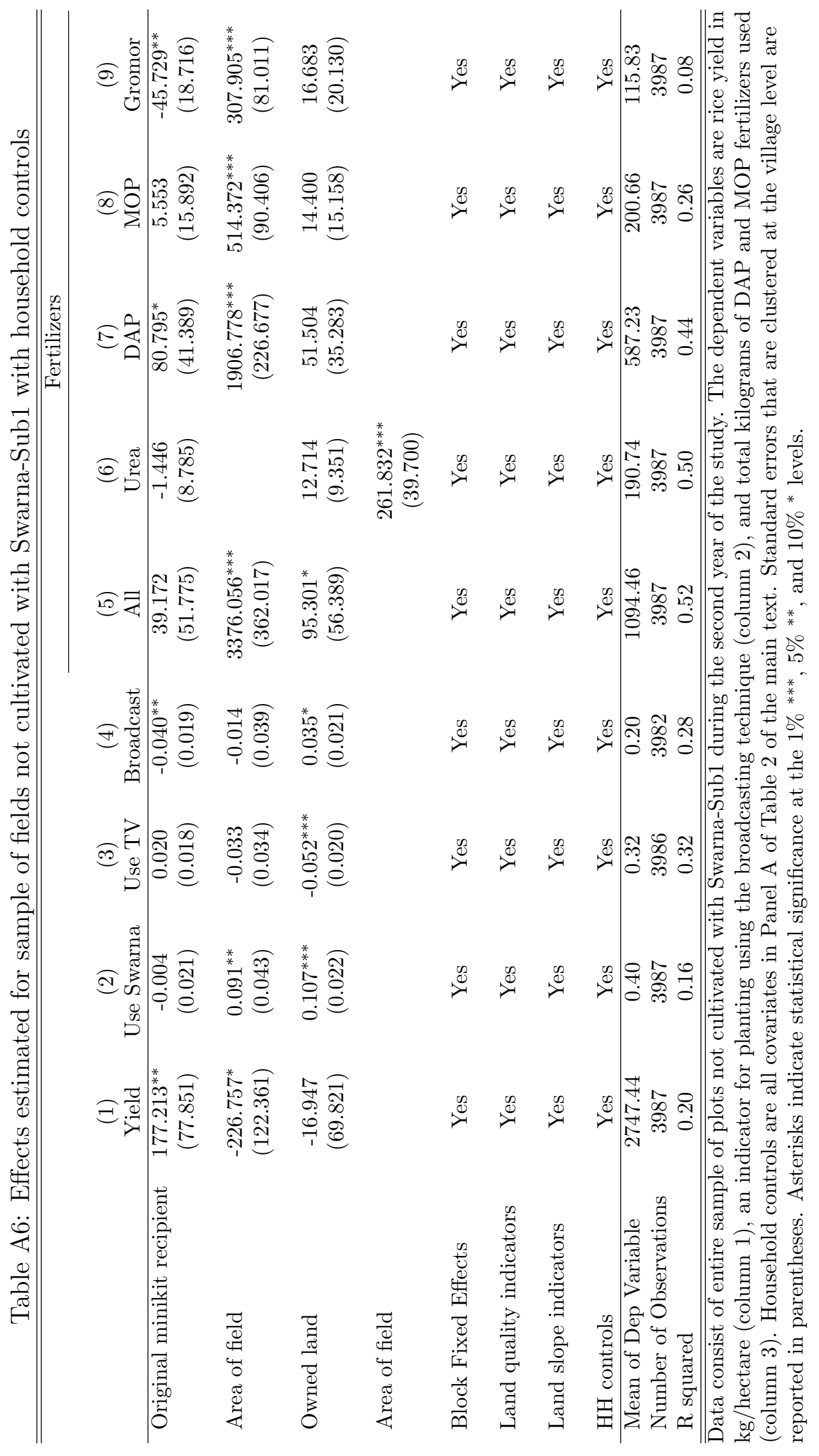


Table A7: Effects on fallowing of plots cultivated in year 1 during year 2

\begin{tabular}{|c|c|c|c|}
\hline & (1) & $(2)$ & $(3)$ \\
\hline $\begin{array}{l}\text { Original minikit } \\
\text { recipient }\end{array}$ & $\begin{array}{l}-0.023^{*} \\
(0.012)\end{array}$ & $\begin{array}{l}-0.018 \\
(0.013)\end{array}$ & $\begin{array}{c}-0.018^{*} \\
(0.010)\end{array}$ \\
\hline Minikit*Low land & & $\begin{array}{l}-0.030 \\
(0.020)\end{array}$ & \\
\hline Low land & & $\begin{array}{c}0.015 \\
(0.016)\end{array}$ & \\
\hline $\begin{array}{l}\text { Minikit*Low quality } \\
\text { land }\end{array}$ & & & $\begin{array}{c}-0.071^{* *} \\
(0.036)\end{array}$ \\
\hline Low quality land & & & $\begin{array}{c}0.119^{* * *} \\
(0.025)\end{array}$ \\
\hline Block Fixed Effects & Yes & Yes & Yes \\
\hline Mean of Dep Variable & 0.08 & 0.07 & 0.07 \\
\hline Number of Observations & 5068 & 5047 & 5012 \\
\hline $\mathrm{R}$ squared & 0.019 & 0.021 & 0.038 \\
\hline
\end{tabular}


Table A8: Decomposition of area effects

\begin{tabular}{lcc}
\hline \hline & $(1)$ & $(2)$ \\
& Number plots & Plot size \\
\hline Original minikit recipient & $0.68^{* * *}$ & $-0.02^{*}$ \\
& $(0.13)$ & $(0.01)$ \\
Block Fixed Effects & & Yes \\
\hline Mean of Dep Variable & 3.57 & 0.27 \\
Number of Observations & 1237 & 4589 \\
R squared & 0.100 & 0.040 \\
\hline \hline
\end{tabular}

The unit of observation is the farmer in column 1 and the plot in column 2. The dependent variable in column 1 is the total number of rice plots cultivated in year two. The dependent variable in column 2 is the size of the plot, measured in hectares. Standard errors that are clustered at the village level are reported in parentheses. Asterisks indicate statistical significance at the $1 \%^{* * *}, 5 \%^{* *}$, and $10 \%^{*}$ levels. 


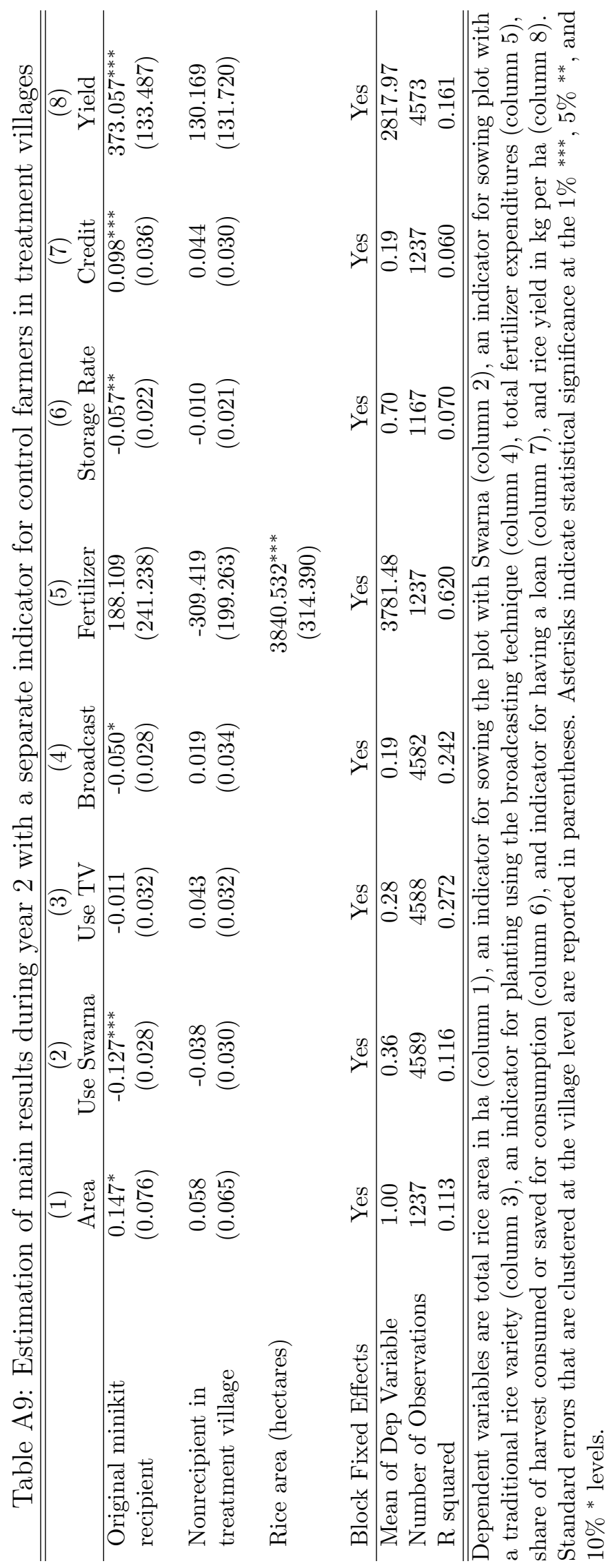


Table A10: Adjustment of p-values for multiple hypothesis testing

\begin{tabular}{lcccc}
\hline Outcome & Mean outcome & Point estimate & Unadj. p-value & FDR adj. p-value \\
\hline Broadcasting & 0.186 & -0.063 & 0.000 & 0.003 \\
Use TV & 0.284 & -0.041 & 0.011 & 0.031 \\
Use Swarna & 0.359 & -0.101 & 0.000 & 0.001 \\
Plot yield & $2,817.971$ & 283.449 & 0.000 & 0.003 \\
Irrigated & 0.737 & 0.033 & 0.267 & 0.315 \\
Log seed rate & 4.158 & -0.041 & 0.037 & 0.068 \\
Plot sharecropped in & 0.155 & -0.021 & 0.169 & 0.226 \\
Rice area, ha & 1.002 & 0.109 & 0.063 & 0.105 \\
Storage rate & 0.696 & -0.050 & 0.004 & 0.019 \\
Has credit & 0.187 & 0.068 & 0.012 & 0.031 \\
Use pesticide & 0.776 & 0.060 & 0.024 & 0.053 \\
Has dry season crop & 0.228 & -0.003 & 0.900 & 0.900 \\
Has ag. labor income & 0.483 & -0.036 & 0.267 & 0.315 \\
Sold rice seeds & 0.052 & 0.016 & 0.337 & 0.375 \\
Has livestock income & 0.369 & -0.076 & 0.010 & 0.031 \\
Extension contact & 0.213 & 0.069 & 0.027 & 0.054 \\
Urea expenditure & 664.704 & 13.428 & 0.697 & 0.734 \\
DAP expenditure & $2,016.799$ & 393.768 & 0.005 & 0.019 \\
MOP expenditure & 702.823 & 90.579 & 0.122 & 0.188 \\
Gromor expenditure & 397.154 & -101.073 & 0.138 & 0.198 \\
\hline
\end{tabular}

The data consists of the agricultural outcome variables from our year 2 follow-up survey. The first column displays the mean value of the outcome variable across the entire sample. The second column gives the point estimate from a regression of the outcome on the farmer-level treatment indicator and block fixed effects. The third column displays p-values that are not adjusted for multiple hypothesis testing. The fourth column shows p-values from Benjamini, Krieger, and Yekutieli (2006) that are adjusted to control the false discovery rate, i.e. the share of rejections of the null that are false. All p-values are based on standard errors that are clustered at the village level. 


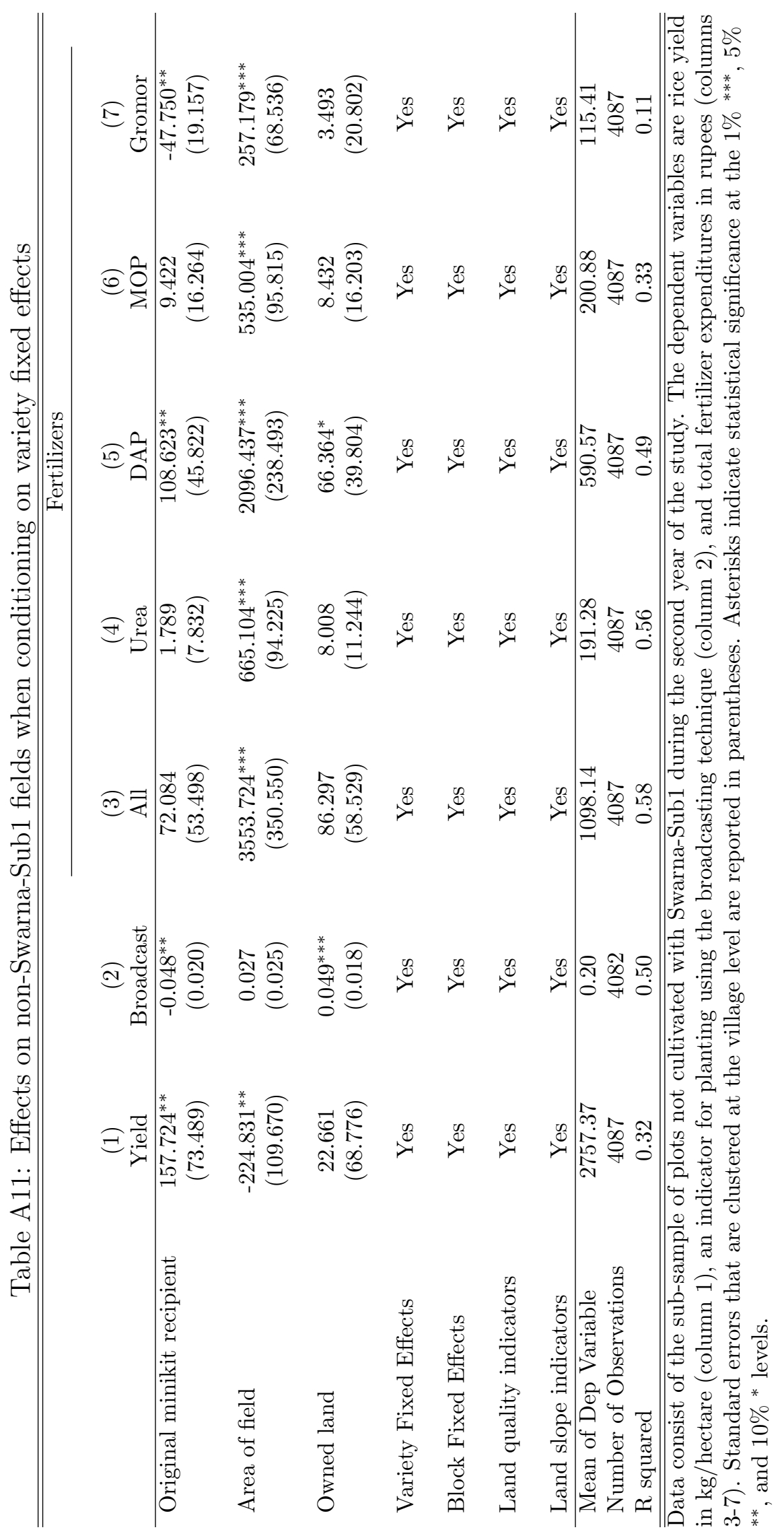


Table A12: Relationship between planting of Swarna-Sub1 and plot-level characteristics

\begin{tabular}{|c|c|c|c|}
\hline & \multicolumn{3}{|c|}{ Farmers: } \\
\hline & $\begin{array}{l}(1) \\
\text { All }\end{array}$ & $\begin{array}{c}(2) \\
\text { Treatment }\end{array}$ & $\begin{array}{c}(3) \\
\text { Control }\end{array}$ \\
\hline Area of field & $\begin{array}{c}-0.079^{* * *} \\
(0.023)\end{array}$ & $\begin{array}{c}-0.189^{* * *} \\
(0.067)\end{array}$ & $\begin{array}{c}-0.016 \\
(0.015)\end{array}$ \\
\hline Owned land & $\begin{array}{c}0.043^{* * *} \\
(0.012)\end{array}$ & $\begin{array}{c}0.113^{* * *} \\
(0.042)\end{array}$ & $\begin{array}{c}0.012 \\
(0.008)\end{array}$ \\
\hline Low land & $\begin{array}{l}-0.020^{*} \\
(0.011)\end{array}$ & $\begin{array}{c}-0.071^{* *} \\
(0.031)\end{array}$ & $\begin{array}{l}-0.002 \\
(0.007)\end{array}$ \\
\hline Bad quality land & $\begin{array}{c}-0.005 \\
(0.015)\end{array}$ & $\begin{array}{c}0.018 \\
(0.038)\end{array}$ & $\begin{array}{c}-0.018^{*} \\
(0.010)\end{array}$ \\
\hline Field has tubewell irrigation & $\begin{array}{c}0.021 \\
(0.019)\end{array}$ & $\begin{array}{l}-0.006 \\
(0.041)\end{array}$ & $\begin{array}{c}0.015 \\
(0.012)\end{array}$ \\
\hline Block Fixed Effects & Yes & Yes & Yes \\
\hline Mean of Dep Variable & 0.10 & 0.26 & 0.04 \\
\hline Number of Observations & 4575 & 1312 & 3263 \\
\hline $\mathrm{R}$ squared & 0.02 & 0.05 & 0.03 \\
\hline
\end{tabular}

The dependent variable in all regressions is an indicator for fields that were planted with Swarna-Sub1. Low land is land that farmers reported was lowest in elevation in the village (on a scale from 1-3). Bad quality land is land that farmers reported to have below-average land quality. Standard errors that are clustered at the village level are reported in parentheses. Asterisks indicate statistical significance at the $1 \%^{* * *}, 5 \%^{* *}$, and $10 \%^{*}$ levels. 
Table A13: Correlates of plot characteristics with minikit treatment for sample of plots not cultivated with Swarna-Sub1

\begin{tabular}{lcc}
\hline \hline & \multicolumn{2}{c}{ Sample: } \\
\cline { 2 - 3 } & $(1)$ & $(2)$ \\
& All & Non-Sub1 trimmed \\
\hline Low land & 0.018 & 0.022 \\
& $(0.022)$ & $(0.022)$ \\
Area of field & -0.033 & -0.027 \\
& $(0.043)$ & $(0.044)$ \\
Bad quality land & 0.027 & 0.026 \\
& $(0.032)$ & $(0.033)$ \\
Owned land & 0.011 & 0.015 \\
& $(0.025)$ & $(0.025)$ \\
Field has tubewell irrigation & 0.068 & 0.065 \\
& $(0.041)$ & $(0.042)$ \\
Block Fixed Effects & Yes & Yes \\
\hline Mean of Dep Variable & 0.24 & 0.25 \\
Number of Observations & 4087 & 3903 \\
R squared & 0.01 & 0.01 \\
\hline \hline
\end{tabular}

The dependent variable in both regressions is an indicator for plots cultivated by treatment farmers.

Column 1 contains all plots that were not cultivated with Swarna-Sub1. Column 2 contains all of these plots, but then drops the lowest-productivity plot of each control farmer with a probability of 0.2354 . Low land is land that farmers reported was lowest in elevation in the village (on a scale from 1-3). Bad quality land is land that farmers reported to have below-average land quality. Standard errors that are clustered at the village level are reported in parentheses. Asterisks indicate statistical significance at the $1 \%^{* * *}, 5 \%^{* *}$, and $10 \% *$ levels. 


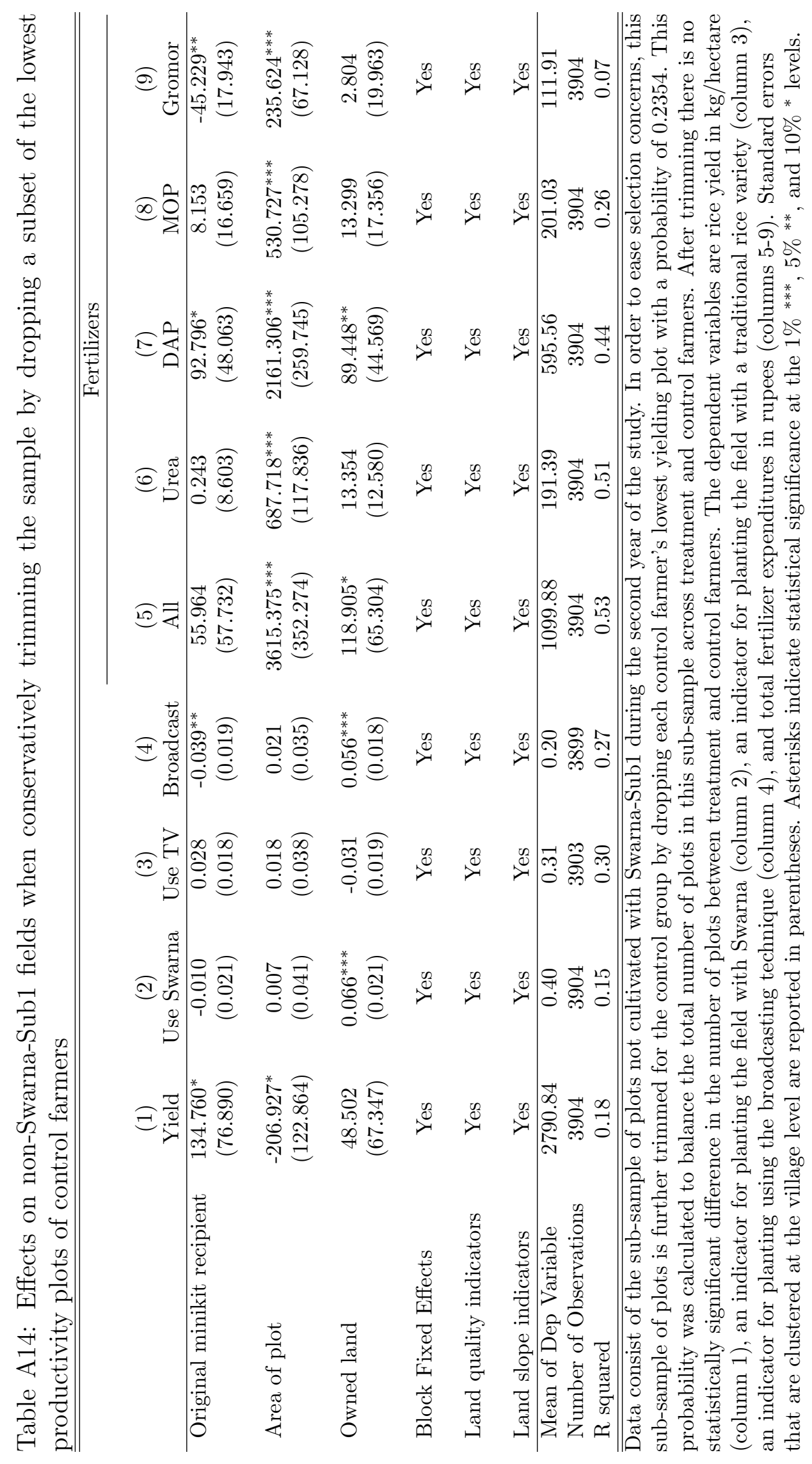


Table A15: Relationship between total rice output and flood exposure during year one for control farmers

\begin{tabular}{lcc}
\hline \hline & $(1)$ & $(2)$ \\
\hline Flood exposure in days & $-90.305^{* * *}$ & $-90.352^{* * *}$ \\
& $(28.715)$ & $(26.765)$ \\
Block Fixed Effects & Yes & Yes \\
& & \\
Household controls & No & Yes \\
\hline Mean of Dep Variable & 1738.91 & 9740.38 \\
Number of Observations & 928 & 0.364 \\
R squared & 0.123 & in
\end{tabular}

The data include observations for control farmers only. The dependent variable in both columns is the total rice harvest during year one. Flood exposure in days is the area-weighted average number of days the farmer's fields were flooded. Household controls are all covariates in Panel A of Table 2 of the main text. Standard errors that are clustered at the village level are reported in parentheses. Asterisks indicate statistical significance at the $1 \%^{* * *}, 5 \%^{* *}$, and $10 \%^{*}$ levels. 
Table A16: Comparison of effects of Swarna-Sub1 treatment with effects of a flood shock with the same expected increase in rice production

\begin{tabular}{lcc}
\hline Outcome & Sub1 treatment & Equivalent flood shock \\
\hline Rice area & $0.109^{*}$ & 0.008 \\
Log rice area & $(0.056)$ & $(0.013)$ \\
& $0.098^{* *}$ & 0.016 \\
Use Swarna & $(0.044)$ & $(0.011)$ \\
& $-0.101^{* * *}$ & -0.002 \\
Use TV & $(0.017)$ & $(0.004)$ \\
& $-0.041^{* *}$ & 0.007 \\
Broadcast planting & $(0.016)$ & $(0.005)$ \\
& $-0.063^{* * *}$ & 0.004 \\
All fertilizer & $(0.017)$ & $(0.007)$ \\
& $396.703^{* *}$ & $-81.134^{*}$ \\
Urea & $(179.631)$ & $(44.627)$ \\
& 13.428 & $-21.017^{*}$ \\
DAP & $(34.372)$ & $(11.149)$ \\
& $393.768^{* * *}$ & -52.922 \\
MOP & $(136.410)$ & $(34.474)$ \\
& 90.579 & -1.992 \\
Gromor & $(58.170)$ & $(14.587)$ \\
Share saved & -101.073 & -5.202 \\
Has credit & $(67.759)$ & $(20.772)$ \\
Yield & $-0.050^{* * *}$ & -0.002 \\
& $(0.017)$ & $(0.004)$ \\
& $0.068^{* *}$ & -0.008 \\
& $(0.027)$ & $(0.006)$ \\
& $283.449^{* * *}$ & -7.548 \\
& $(77.484)$ & $(21.127)$ \\
\hline
\end{tabular}

Each entry in the table is from a separate regression. Entries in the first column are the effects of the Swarna-Sub1 treatment as reported in Tables 3 to 6 . Each regression in column 2 shows the coefficient from a regression of the listed outcome variable on the number of flood days the farmer was exposed to in year 1 divided by 1.4, controlling for block fixed effects. This "equivalent shock" variable is constructed so that a one unit decrease is equivalent to 126.67 kilograms of rice, which is the expected output gain that treatment farmers could expect from planting 0.33 hectares of area with Swarna-Sub1. The regressions in column 2 use observations from the control group only. Standard errors in parentheses are clustered at the village level for all regressions. Asterisks indicate statistical significance at the $1 \%^{* * *}, 5 \%^{* *}$, and $10 \%^{*}$ levels. 
Table A17: Estimation of main results conditioning on the year 1 rice harvest

\begin{tabular}{|c|c|c|c|c|c|c|}
\hline & \multicolumn{3}{|c|}{ Plot level } & \multicolumn{3}{|c|}{ Farmer level } \\
\hline & (1) & (2) & (3) & (4) & (5) & (6) \\
\hline & Yield & Use TV & Broadcast & Fertilizer & Share saved & Credit \\
\hline $\begin{array}{l}\text { Original minikit } \\
\text { recipient }\end{array}$ & $\begin{array}{c}275.834^{* * *} \\
(77.658)\end{array}$ & $\begin{array}{c}-0.039^{* *} \\
(0.016)\end{array}$ & $\begin{array}{c}-0.062^{* * *} \\
(0.017)\end{array}$ & $\begin{array}{l}350.188^{*} \\
(182.558)\end{array}$ & $\begin{array}{c}-0.043^{* *} \\
(0.017)\end{array}$ & $\begin{array}{l}0.065^{* *} \\
(0.027)\end{array}$ \\
\hline $\begin{array}{l}2011 \text { rice harvest } \\
\text { (tons) }\end{array}$ & $\begin{array}{c}21.122 \\
(16.863)\end{array}$ & $\begin{array}{l}-0.005 \\
(0.004)\end{array}$ & $\begin{array}{l}-0.004 \\
(0.003)\end{array}$ & $\begin{array}{c}216.455^{* *} \\
(95.097)\end{array}$ & $\begin{array}{c}-0.022^{* * *} \\
(0.004)\end{array}$ & $\begin{array}{c}0.009 \\
(0.006)\end{array}$ \\
\hline Rice area (hectares) & & & & $\begin{array}{c}3540.807^{* * *} \\
(375.751)\end{array}$ & & \\
\hline Block Fixed Effects & Yes & Yes & Yes & Yes & Yes & Yes \\
\hline Mean of Dep Variable & 2817.97 & 0.28 & 0.19 & 3781.48 & 0.70 & 0.19 \\
\hline Number of Observations & 4573 & 4588 & 4582 & 1237 & 1167 & 1237 \\
\hline $\mathrm{R}$ squared & 0.161 & 0.271 & 0.243 & 0.627 & 0.102 & 0.060 \\
\hline
\end{tabular}

Estimation data are at the plot level in columns 1-4 and the farmer level in columns 5-8. Dependent variables are rice yield in $\mathrm{kg} / \mathrm{ha}$ (column 1 ), an indicator for sowing plot with a traditional rice variety (column 2), an indicator for planting using the broadcasting technique (column 3), an indicator for plot not being cultivated (column 4), total fertilizer use (column 5), number of plots cultivated with rice (column 6 ), share of harvest consumed or saved for consumption (column 7), and indicator for access to credit (column 8). Standard errors that are clustered at the village level are reported in parentheses. Asterisks indicate statistical significance at the $1 \%^{* *}, 5 \%^{* *}$, and $10 \%^{*}$ levels. 


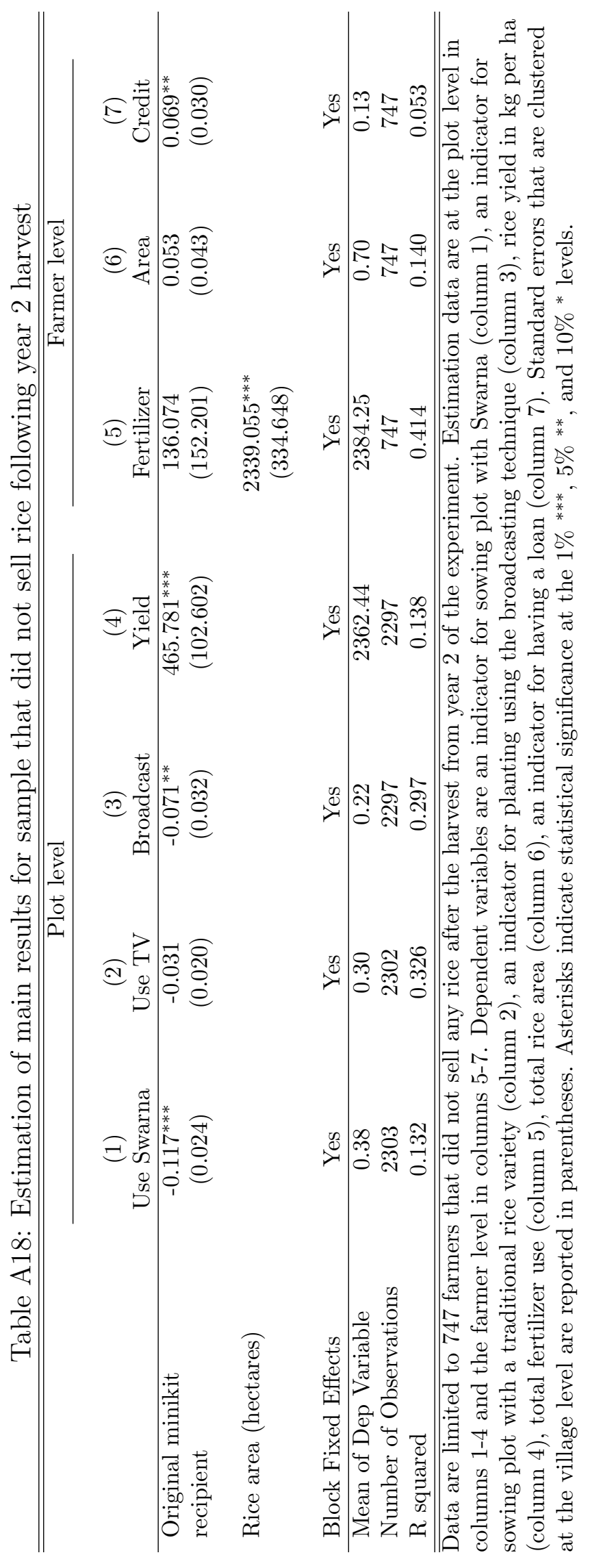

